\title{
Central Nervous System Tuberculosis
}

\author{
Shahina Bano, Vikas Chaudhary ${ }^{2}$ and Sachchidanand Yadav 3 \\ ${ }^{1}$ Department of Radiodiagnosis, G.B. Pant \\ Hospital \& Maulana Azad Medical College, New Delhi \\ 2Department of Radiodiagnosis, Employees' State Insurance \\ Corporation (ESIC) Model Hospital, Gurgaon, Haryana \\ ${ }^{3}$ Department of Radiodiagnosis, Dr. Ram Manohar \\ Lohia Hospital \& PGIMER, New Delhi, \\ India
}

\section{Introduction}

Tuberculosis is a formidable disease worldwide because of its highly infectious nature and propensity for latency. The increasing prevalence of tuberculosis in both immunocompetent and immunocompromised individuals in recent years makes this disease a topic of universal concern. The disease has insidious onset and can affect virtually any organ system in the body, including the central nervous system (CNS). The CNS tuberculosis can mimic a number of other disease entities, and therefore it is important to be familiar with the various radiologic features of CNS tuberculosis to ensure early, accurate diagnosis. In this chapter we discuss various possible presentation of central nervous system tuberculosis involving the brain and spine.

\section{Pathophysiology}

Most tuberculous infections of the central nervous system are caused by Mycobacterium tuberculosis, as a result of hematogenous spread from a primary location, either the lung or gastrointestinal tract. Initially, small tuberculous lesions (Rich's foci) develop in the CNS, either during the stage of bacteraemia of the primary tuberculous infection or shortly afterwards. These initial tuberculous lesions may be inoculated in the meninges; the subpial and subependymal surface of the brain or the spinal cord, and may remain dormant for years. Later, rupture or growth of one or more of these small tuberculous lesions produces various types of CNS tuberculosis. The type and extent of lesion depend upon the number and virulence of bacilli and the immune response of the host. ${ }^{1} \mathrm{~A}$ tubercular rupture into the subarachnoid space results in TB meningitis; where as deep lesions cause tuberculoma or abscesses. TB meningitis may cause inflammatory changes in cranial/spinal nerves and the blood vessels. The inflammation of blood vessels (vasculitis) subsequently results in thrombosis and infarction. Hydrocephalous can occur secondary to impedance of CSF circulation and absorption. The inflammatory exudates may also surround the spinal cord producing tuberculous arachnoiditis. Infrequently, infection spreads to the CNS from a site of discal TB, tuberculous otitis, or osteogenic tubercular foci in the spine or cranial vault. ${ }^{2}$

Pathologically, a tuberculoma is composed of central core of caseous necrosis surrounded by a capsule of collagenous tissues and an outer layer of mononuclear inflammatory cells (including plasma cells \& lymphocytes), epitheloid cells and multinucleated Langerhans' 
giant cells. A tuberculoma harbours few tubercular bacilli within the necrotic center and the capsule. Outside the capsule, there is parenchymal edema and astrocyte proliferation. Unlike caseous tuberculoma, a tubercular abscess has purulent center rich in tubercular bacilli, and lacks epithelioid giant cell granulomatous reaction in its wall. ${ }^{3}$

\section{Clinical features}

CNS TB usually has signs and symptoms of increased intracranial pressure or spaceoccupying lesions in the brain or spine. Signs of meningitis includes constitutional symptoms (such as low grade fever, headache, nausea, vomiting, lethargy), meningismus, confusion, seizure, papilloedema, cranial nerve palsies (commonly second, third, fourth, sixth and seventh nerves), focal neurological deficits, stupor and coma. Patients with brain and spinal cord tuberculomas will have physical signs and symptoms consistent with the location of the lesion, which may include altered mental status, visual changes, hemiparesis/hemiplegia or seizure as seen with brain lesions; while weakness of extremities or bowel and bladder symptoms as seen with spinal cord lesions. 4,5

\section{Classification of cns tuberculosis}

The manifestations of CNS tuberculosis are highly variable; however we have tried to include various possible presentations of CNS tuberculosis in this chapter as summarized in the box 1 given below:

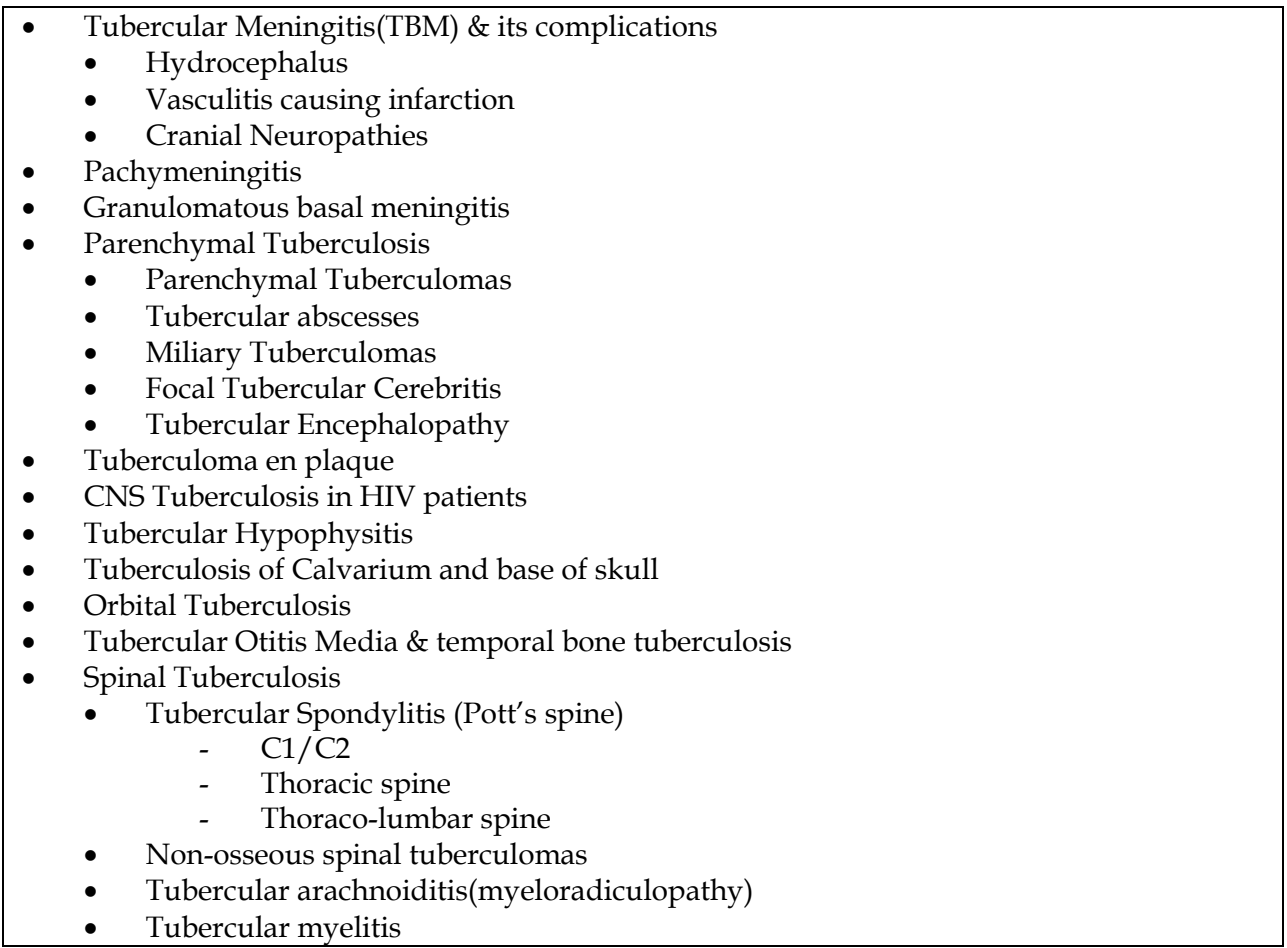

Box 1. Variable presentation of CNS tuberculosis 


\section{Imaging features}

\subsection{Tuberculous meningitis}

Tuberculous meningitis (TBM) is the most common presentation of CNS TB and is seen most frequently in children and adolescents. TBM develops when a meningeal, subpial or subependymal tuberculous focus (Rich focus) ruptures into the subarachnoid space or into the ventricular system. Important features of TBM are: 6

1. Enhancing basal exudates

2. Progressive hydrocephalus

3. Vasculitis \& Infarction, and

4. Cranial neuropathies

\subsubsection{Basal exudates}

In tuberculous meningitis, there is formation of thick, gelatinous exudate as a result of cellmediated immunity. Initially the exudate is largely confined to basal subarachnoid areas, but rapidly extends to involve the basal cisterns, particularly the interpeduncular and the suprasellar cisterns. From these sites the exudate spreads to the ambient cistern, prepontine cistern, sylvian fissures, cerebral convexities, to the ependymal surfaces of the ventricles and over choroid plexus. 7,8 On noncontrast $\mathrm{CT}$, the most common finding of cranial tuberculous meningitis is obliteration of basal cistern by isodense or slightly hyperdense exudates. Contrast enhanced CT demonstrates thickening and intense homogenous enhancement of the basal meninges, giving characteristic spider leg appearance [figure1]. MRI is more sensitive than CT in depicting these abnormalities. The basal exudates are best appreciated on FLAIR sequences, while the cisternal enhancement is better demonstrated on postgadolinium MRI images [Fgure2]. ${ }^{9}$ The brain parenchyma immediately beneath the exudate shows various degrees of edema. The meningeal enhancement can extend over the surface of the brain convexities, along tentorium and the sylvian fissures.6,7 Isolated sylvian fissure involvement by tuberculous meningitis is also known. ${ }^{10}$ Extension into the ventricular system may cause ependymitis (abnormal enhancement of ventricular linings), or choroid plexitis (enlarged, enhancing choroid plexus).7,8

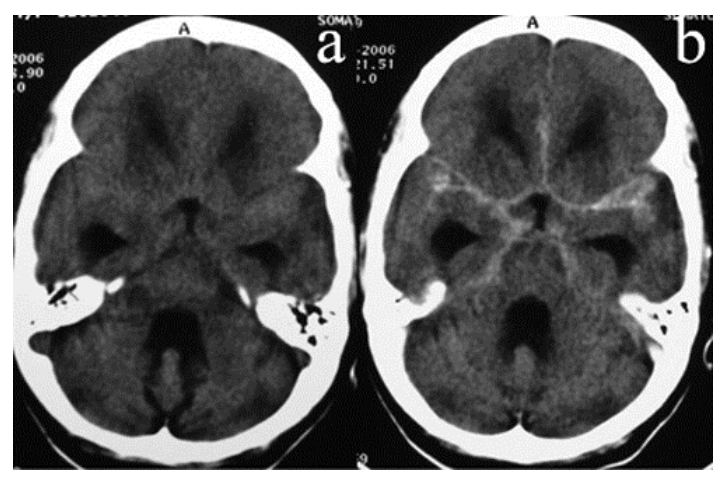

Fig. 1. Tuberculous meningitis. NCCT scan of the brain(a) shows effacement of basal cisterns by isodense exudates. CECT scan(b) shows dense enhancement of thickened and inflamed basal meninges along the basal cisterns (giving characteristic spider leg appearance), tentorium and the sylvian fissure with evidence of hydrocephalus and periventricular ooze. 

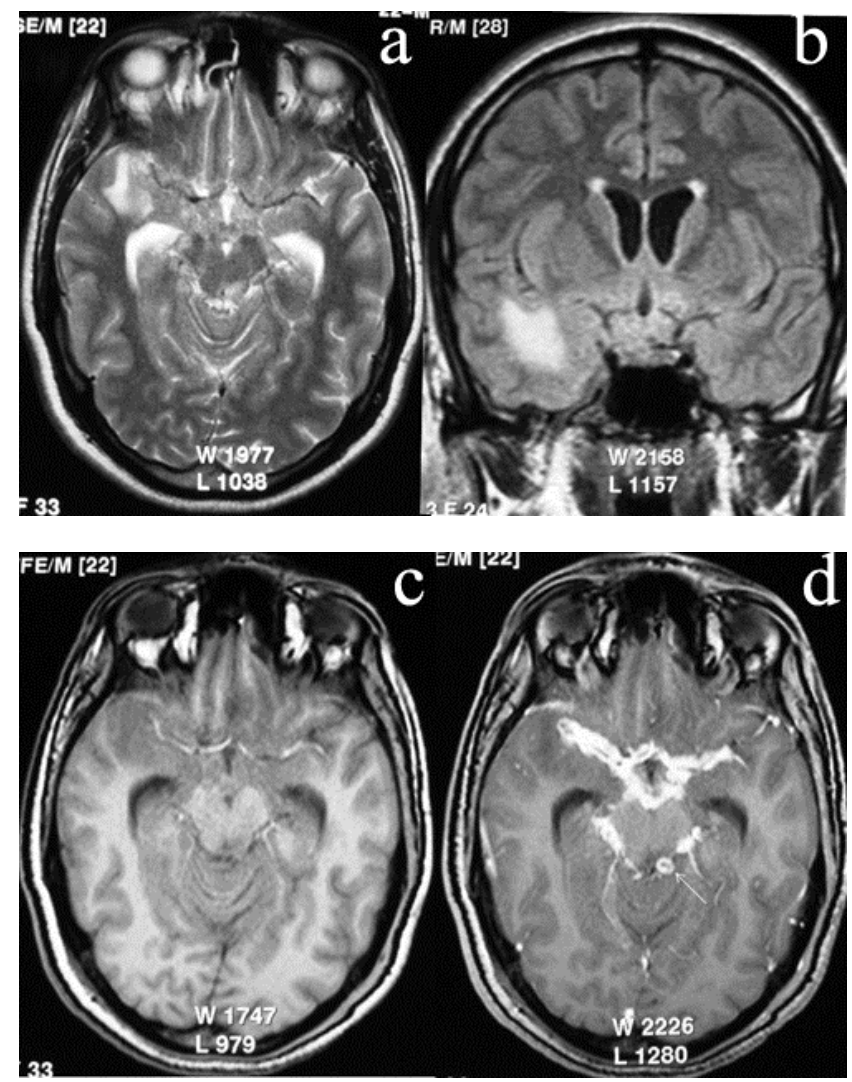

Fig. 2. Tuberculous meningitis. Axial T2W(a), and Fluid attenuated inversion recovery(b) MR images shows abnormal complex hyperintensity in the suprasellar, interpeduncular and perimesencephalic cisterns. Axial T1W(c) and corresponding post contrast image demonstrates diffuse enhancement of the basal cisterns. Few ring-enhancing tuberculomas (arrow) are also noted within the cistern.

\subsubsection{Hydrocephalus}

Hydrocephalus is the most common sequel of tuberculous meningitis. Communicating hydrocephalus [Figure1,2] is the most frequently observed form, usually caused by obstruction to CSF flow by thick gelatinous inflammatory exudates within the basal cisterns and over the brain convexities.11,12 Less commonly, the hydrocephalus may be obstructive, due to obstruction of cerebral aqueduct or fourth ventricular foramen by focal parenchymal lesion with mass effect or due to entrapment of the ventricle by granulomatous ependymitis. ${ }^{13,14}$ The presence of periventricular ooze suggests high pressure hydrocephalus. The incidence of hydrocephalus increases with the duration of disease and is associated with poor prognosis especially in children. The progress of hydrocephalus may be followed up by sequential CT or MRI scan. 15 


\subsubsection{Vasculitis \& infarction}

In TB meningitis, the basal exudates are maximally localized to the circle of Willis, and produce a vasculitis like syndrome. The vasculitis is initiated by either direct invasion of vessel wall by mycobacteria or may result from secondary extension of adjacent arachnoiditis. Thus a consequent inflammatory change in the arteries and veins may lead to spasm or thrombosis of the vessels with resulting infarction. ${ }^{6}$ The vessels at the base of the brain are most severely affected, including the terminal segment of common carotid artery and proximal segment anterior, middle and posterior cerebral arteries.10,16,17 The middle cerebral and its branches are most often affected, especially the medial striate and thalamoperforating arteries supplying the basal ganglia and thalami. ${ }^{14,16,17}$ Cortical infarctions resulting from the involvement of cortical vessels are less common. The infarcts are commonly bilateral, often hemorrhagic, and relatively more common in infants and children than in adults. Although both CT and MRI can demonstrate the infarction, MRI is more sensitive than CT for demonstration of these infarcts. Infarcts appear as low density regions on CT scan, while as areas of prolonged T1 and T2 relaxation on MR images. Diffusion weighted images (DWI) are gold standard for the diagnosis of acute infarction, which appears bright on DWI, and shows decrease signal on corresponding apparent diffusion coefficient(ADC) map[Figure3]. MR angiography is useful in follow-up of patients with vasculitis secondary to TB meningitis. The angiogram demonstrates a triad of narrowing of arteries at the base of the brain, narrowed or occluded small or medium sized arteries with early draining veins, and wide sweep of pericallosal arteries secondary to hydrocephalus [Figure4]. ${ }^{16,17}$

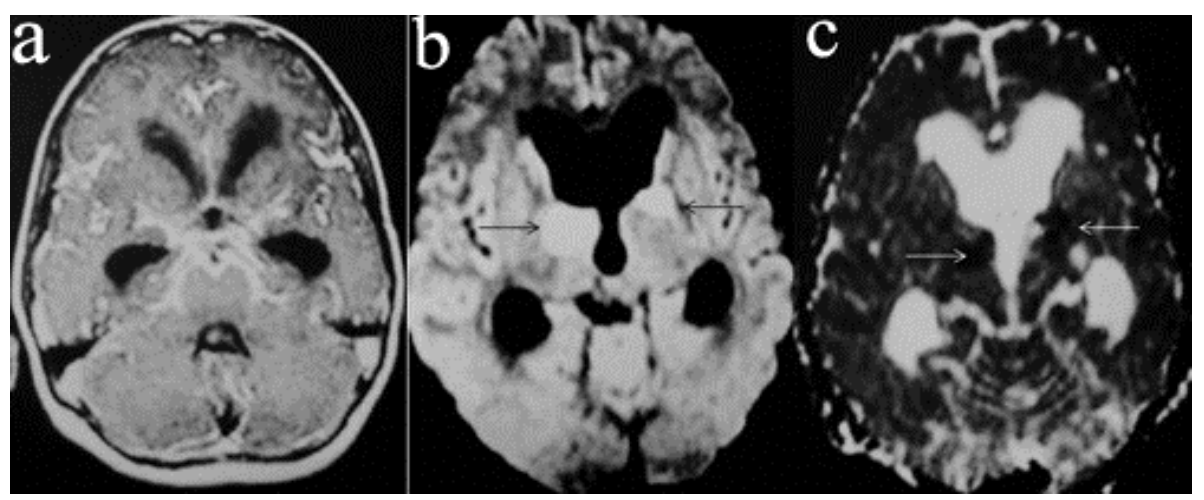

Fig. 3. Tuberculous meningitis with acute infarct. Post contrast axial MR image (a) shows enhancing basal exudates with associated hydrocephalus. Diffusion weighted image(b) and corresponding apparent diffusion coefficient(c) mapping reveals acute infarct in bilateral basal ganglia (due to vasculitis) showing high signal intensity on b1000 and low signal intensity on ADC map. 


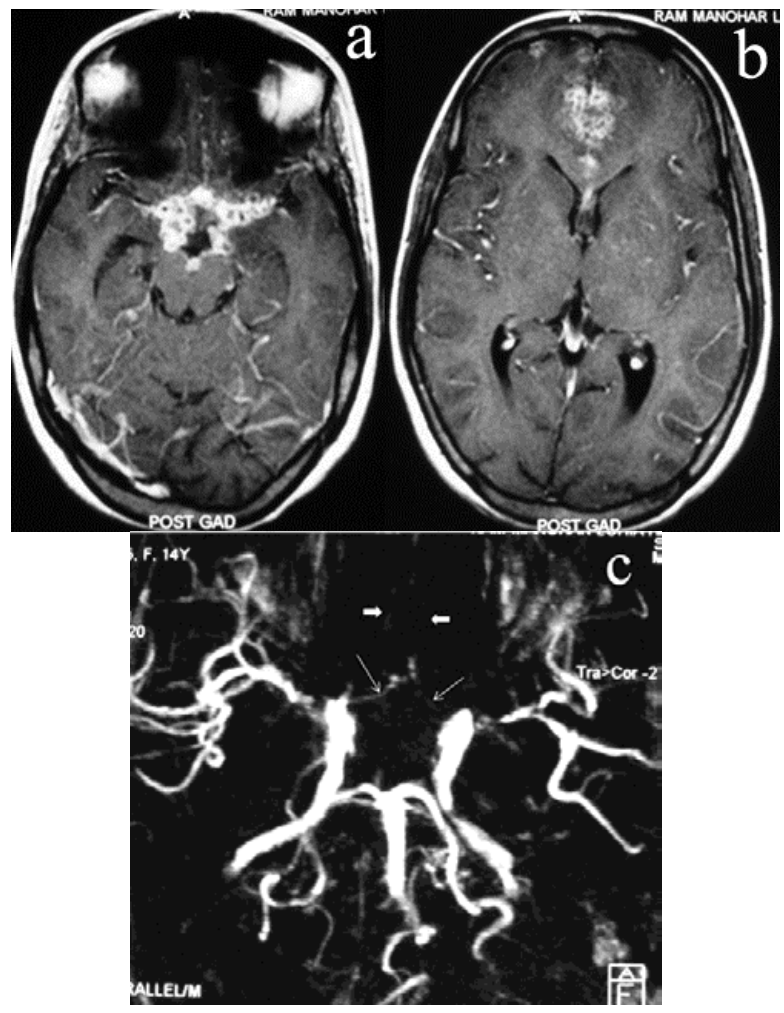

Fig. 4. Basal granulomatous meningitis with vascular changes. Axial T1W post contrast MR images of the brain at two different levels $(a, b)$ shows basal meningitis with multiple conglomerate tuberculomas in suprasellar cistern and along anterior interhemispheric fissure. TOF MR angiogram(c) demonstrates severe narrowing of bilateral anterior cerebral arteries(thin arrows), and splaying of pericallosal arteries (thick arrows) by these conglomerate masses.

\subsubsection{Cranial neuropathies}

Cranial nerve palsies occurs in $20-40 \%$ of patients and may be the presenting feature of TB meningitis. Cranial nerve involvement is partly due to vascular compromise resulting in ischemia of the nerve or may be due to entrapment of the nerves by the exudates. Most commonly affected cranial nerves are II, III, IV, VI, VII. The affected cranial nerves are best evaluated by MRI. They appear thickened and hyperintense on T2-weighted sequences, and show marked enhancement on postgadolinium images. Constructive Interference at Steady State (CISS), which is a T2-weighted, 3D-Gradient echo sequence is particularly used for evaluating cranial nerves around the brain stem. Optochiasmatic arachnoiditis, compression of optic chiasma by third ventricular dilatation (in case of hydrocephalus) and optic nerve granuloma are common factors associated with vision loss in these patients. On MRI optochiasmatic arachnoiditis is characterized by perichiasmal enhancement (of basal exudates), hypertrophy and enhancement of chiasma and cisternal segment of both optic nerves. Associated dilatation of third and lateral ventricles is also evident.7,8,19,20 


\subsection{Pachymeningitis}

Chronic tubercular infection of dura mater results in pachymeningitis, a rare manifestation, seen as focal or diffuse thickening and enhancement of the dura. Common sites include cavernous sinus, floor of middle cranial fossa, tentorium and the cerebral convexity. On noncontrast $\mathrm{CT}$, the affected dura has plaque like appearance with or without calcification. On MRI, thickened dura appears hypointense to gray matter both on T1 and T2-weighted images. Post contrast study shows intense homogenous enhancement of thickened pachymeninges [Figure5]. Important differential diagnosis includes neurosarcoidosis, meningioma and lymphoma. ${ }^{21}$

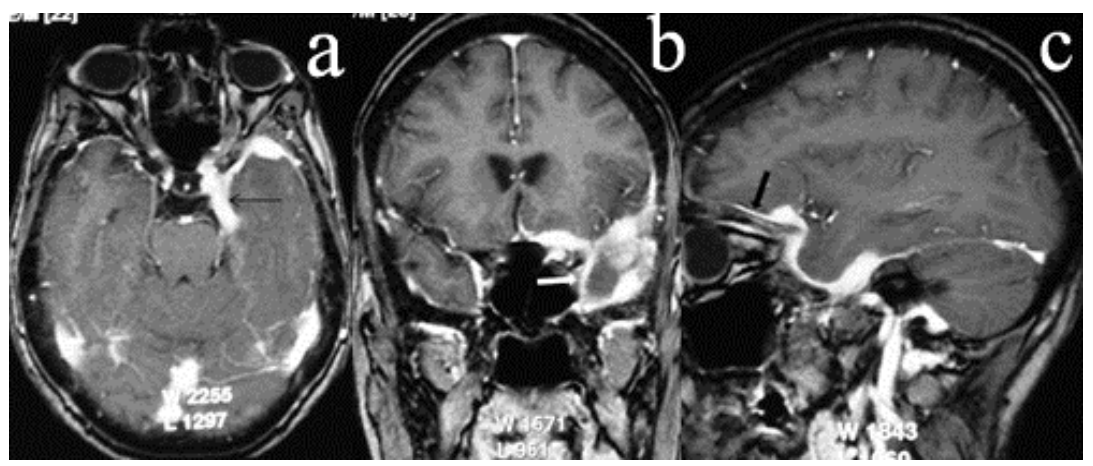

Fig. 5. Pachymeningitis. Post contrast T1W axial(a), coronal(b) and sagittal(c) images of brain show intensely enhancing, thickened pachymeninges(dura mater) encircling the left temporal lobe(thick white arrow), floor of ipsilateral anterior cranial fossa (thick black arrow) and the left cavernous sinus (thin black arrow). The process seems to be progressive with further extension to involve ipsilateral tentorium and cerebral convexity, where dura appears mild thickened.

\subsection{Granulomatous basal meningitis}

Granulomatous basal meningitis is another, relatively uncommon presentation of intracranial tuberculosis. It is characterised by diffuse or circumscribed granulomatous involvement of meninges at the skull base. It commonly causes compression of optic nerves and the optic chiasma producing visual disturbances. On CT scan, it is seen as an irregular lumpy enhancing mass, superimposed on dense basal enhancement. On MRI, the granulomatous basal mass is hypointense on T2-weighted images and shows intense but heterogeneous postgadolinium enhancement. 9,22

\subsection{Parenchymal tuberculosis}

\subsubsection{Parenchymal tuberculomas}

Tuberculous granuloma (tuberculoma) is the most common form of parenchymal lesion. ${ }^{6}$ Tuberculoma can occur at all age group; however, its incidence is higher in pediatric population. ${ }^{11}$ These are usually located at corticomedullary junction and periventricular region, as expected for hematogenous dissemination. They are mostly infratentorial in children, and supratentorial in adults.23,24 Common locations where tubercuomas can be found includes cerebrum, cerebellum, brainstem, basal ganglia, subarachnoid space, cisterns and fissures Rarely, they can be found within the ventricle (lateral ventricle being the most 
common site), cavernous sinus, sella turcica, hypophysis, hypothalamus, sphenoid sinus and mastoid air cells.25,26 Parenchymal tuberculomas can be single or multiple, with or without coexisting meningitis. ${ }^{27}$ Both the parenchymal and intraventricular tuberculoma may be associated with hydrocephalus. ${ }^{28}$

On CT, the noncaseating granulomas are solid, isodense or hyperdense in attenuation and show homogenous contrast enhancement, while the caseating granulomas enhance peripherally. Moderate to marked perilesional edema is frequently present. The 'target sign' seen on CECT is characterized by a central calcific nidus surrounded by rim of enhancement. This sign is highly suggestive of, but not pathognomonic of tuberculosis.29,30 Solitary ring enhancing lesion on $\mathrm{CT}$ in patients presenting with seizures present a diagnostic dilemma since the granuloma of tuberculosis and cysticerus both may have similar morphological appearances. Some authors have tried to differentiate these two entities on basis of clinical signs and radiological (CT) findings. In patients with tuberculoma there is evidence of raised intracranial tension with progressive neurological deficit. The ring enhancing lesion is usually greater than $20 \mathrm{~mm}$ in size, show irregular margin and cause midline shift. On contrary, neurocysticercus granuloma is less than $20 \mathrm{~mm}$ in size, rounded disc like with no significant mass effect. Enlarging lesions on repeat CT after 8-12 weeks of anticonvulsant therapy could be due to different etiologies and should be biopsied. 31

The MR features of individual tuberculoma will depend on whether the lesion is noncaseating, caseating with a solid center or caseating with a liquid center. ${ }^{32,33}$ The Noncaseating granuloma is usually hypointense on T1-weighted images(T1WI), hyperintense on T2-weighted images(T2WI) and shows homogenous nodular enhancement on post gadolinium images. The caseating granuloma(s) with solid center [Figure6]. appears hypointense to isointense on T1WI (may have a slight hyperintense rim) and strikingly hypointense on $\mathrm{T} 2 \mathrm{~W}$ images. On contrast administration the lesion shows peripheral rim enhancement. The relative hypointensity on T2WI is attributed to high cellular density of central core of tuberculoma. The caseating granuloma with central liquefaction of caseous material appears hypointense on T1WI and hyperintense on T2WI with peripheral hypointense rim which represents the capsule of tuberculoma. The rim enhancement occurs after gadolinium administration. These lesions are indistinguishable from pyogenic abscess on imaging. At this stage, diffusion weighted images(DWI) may reveal diffusion restriction within the tuberculoma [Figure6]. ${ }^{34}$ A variable degree of vasogenic edema surrounds the lesion, and is relatively more prominent in the early stages of granuloma formation.

MR spectroscopy has been used to differentiate tuberculoma from pyogenic abscesses and neoplasms (both primary and secondary). On proton MRS [Figure6], these lesions show a large lipid peak at $0.9,1.3,2.0$ and 2.8 ppm, highly specific for tuberculomas, more choline and less NAA and creatine. The choline/creatine ratio is greater than 1 in all tuberculomas. Caseous material typical of tuberculomas has high lipid content. ${ }^{35}$ Pyogenic brain abscesses show lipid and lactate peak at $1.3 \mathrm{ppm}$ and amino acid peak (e.g. valine, leucine and isoleucine) at $0.9 \mathrm{ppm} .{ }^{36}$ The lesions such as metastases and high grade gliomas may show lipid peak in addition to significantly elevated Choline/NAA ratio. ${ }^{35}$

Magnetization transfer imaging (MTI) improves the detectability of these lesions with more number of tuberculomas detected on precontrast T1-weighted MT-SE images, compared to routine spin echo (SE) sequences and postcontrast T1-weighted MT-SE images. 
Conventional SE invisible lesions (isointense on T1-and T2-weighted images) can be easily picked up on MT images because of lower transfer of magnetization in tuberculomas as compared to surrounding brain parenchyma. The presence of lipid within tuberculoma is probably responsible for lowering magnetization transfer. Detection of more lesions on precontrast T1-weighted MT-SE image as compared to postcontrast T1-weighted MT-SE image suggests lack of breach of the blood-brain barrier in some of the lesions. Thus the improved estimate of disease load on precontrast T1-weighted MT-SE images helps to better assess to response to specific therapy. The Quantitative MT (i.e. MT ratio) further helps to differentiate T2 hypointense tubercular granulomas from similar appearing lesions of neurocysticercosis. The MT ratio is significantly lower in tuberculomas as compared to cysticercus granulomas. ${ }^{37}$
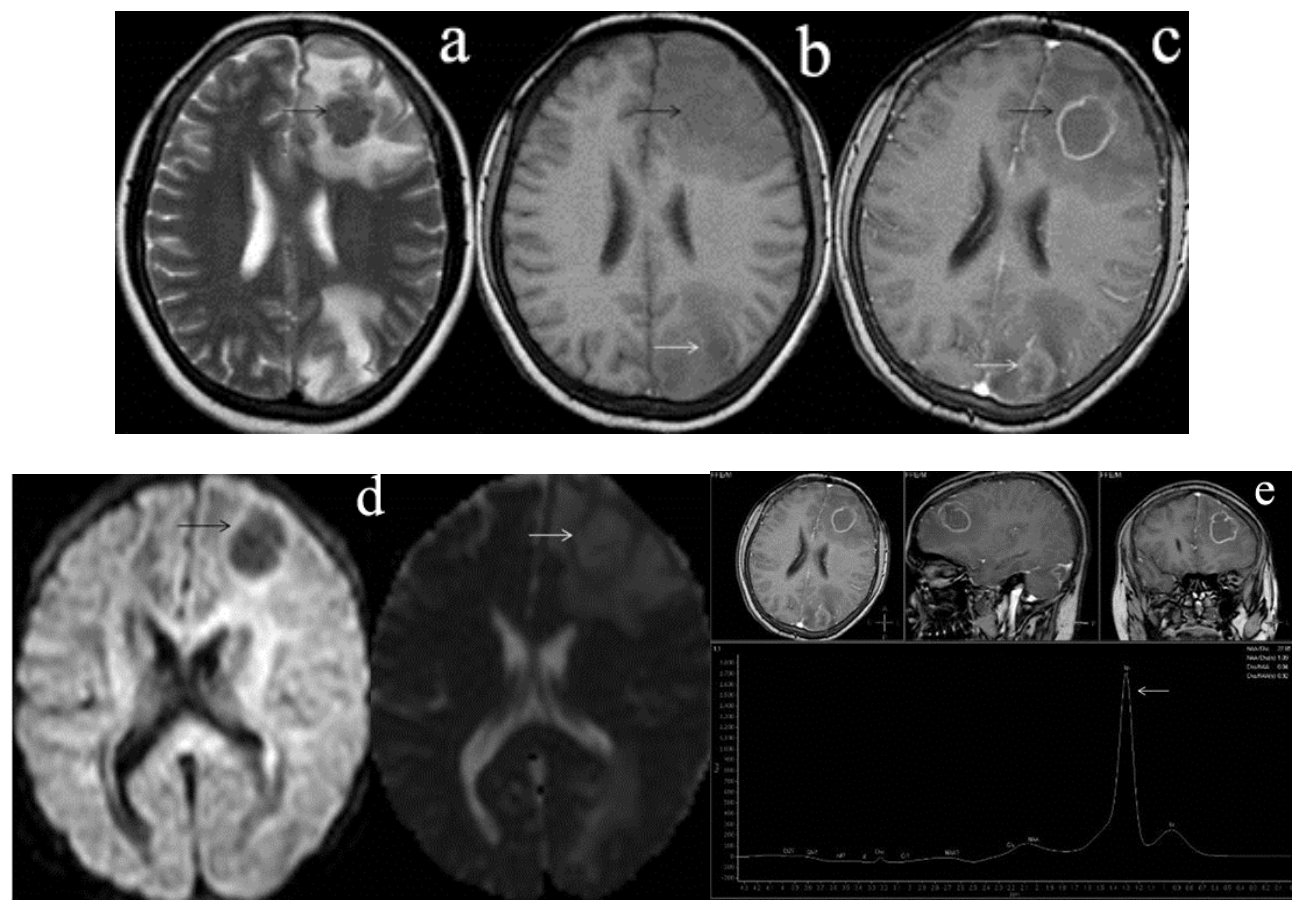

Fig. 6. Caseating tuberculoma. Axial T2W MR image(a) of brain shows profoundly hypointense lesion in left frontal lobe(black arrow) with marked perilesional oedema. The lesion demonstrates isointense core with slight hyperintense rim on T1W image(b), and thin peripheral ring enhancement on gadolinium-enhanced image(c). Multiple similar lesions were present involving both supra and infratentorial compartments, note similar lesion in left occipito-parietal region(white arrow). The solid portion of the lesion shows no diffusion restriction on DWI and corresponding ADC mapping(d). Single voxel MR spectroscopy(e) done at $\mathrm{TE}=30$ shows large lipid peak at $1.33 \mathrm{ppm}$ (arrow), with marked reduction in other metabolites. Large lipid peak corresponds to high lipid content within the caseous material. 
Healed tuberculomas and the inflammatory exudates may calcify (in up to $23 \%$ cases) and these are more evident on CT [Figure7]. On MRI, the calcifications are better appreciated on gradient recalled echo (GRE- T2*WI) and Susceptibility weighted images (SWI). ${ }^{30}$ Multiple conglomerate tuberculomas generally impose no difficulty in making a correct diagnosis; however, a solitary parenchymal tuberculoma needs to be differentiated from neurocysticercosis, pyogenic abcesses, primary or metastatic neoplasm.

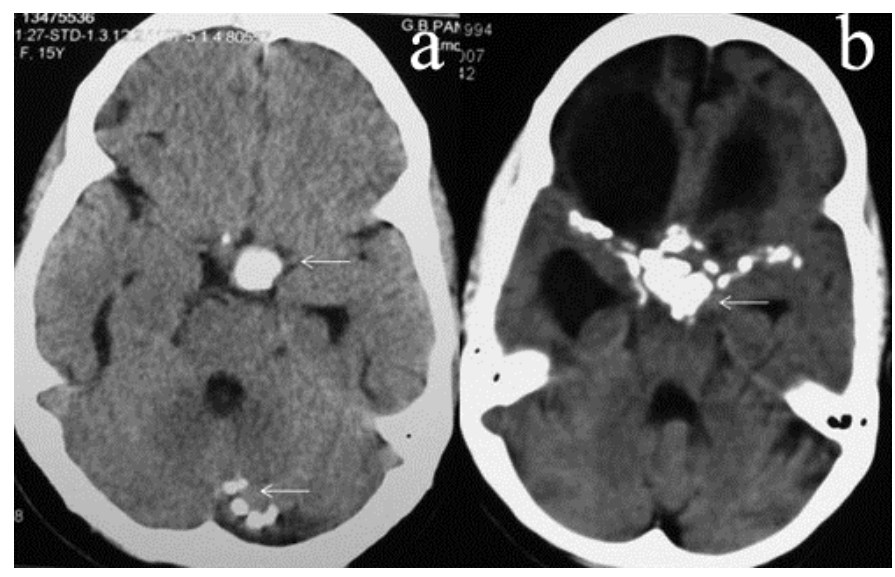

Fig. 7. Healed tuberculomas and basal exudates. Axial NCCT brain of two different patients demonstrate discrete calcified granulomas (arrow) in suprasellar cistern and left cerebellar hemisphere(a), and densely calcified basal exudates(arrow) in suprasellar region and along the M1 segment of bilateral middle cerebral arteries(b).

\subsubsection{Tubercular abscesses}

Tubercular abscess is a rare manifestation of CNS tuberculosis, occurring in less than $10 \%$ cases. They are found more frequently in elderly and immunocompromised patients. The patient is acutely ill with focal neurological deficit. TB abscesses have a more accelerated clinical course. ${ }^{24}$

On imaging, a TB abscess may be indistinguishable from a caseous tuberculoma with central liquefaction or a pyogenic abscess. However, a TB abscess is usually solitary and larger than tuberculoma. Perilesional edema and mass effect is more as compared to tuberculoma. On CT and MRI [Figure 8], it is often multinucleated and shows thin, smooth peripheral wall enhancement on post contrast images. ${ }^{38}$ Proton MRS and MTI help to differentiate tuberculous from pyogenic brain abscesses. On MRS, a pyogenic abscess demonstrates amino acid peak at $0.9 \mathrm{ppm}$, which is characteristically absent in tubercular abscess. On MTI, MT ratio of a tubercular abscess is lower than that found in pyogenic abscess. ${ }^{36}$ The role of DWI is conflicting in making correct diagnosis of tuberculoma as well as tubercular abscess. The reports in the literature vary regarding findings on diffusion weighted images with regard to both the tuberculoma and tubercular abscess. Some papers report slightly increased diffusivity in tuberculoma, and significantly higher in tubercular abscesses, 36 others report decreased diffusivity, ${ }^{39}$ while still others report diffusion characteristic similar to the normal brain. 40 


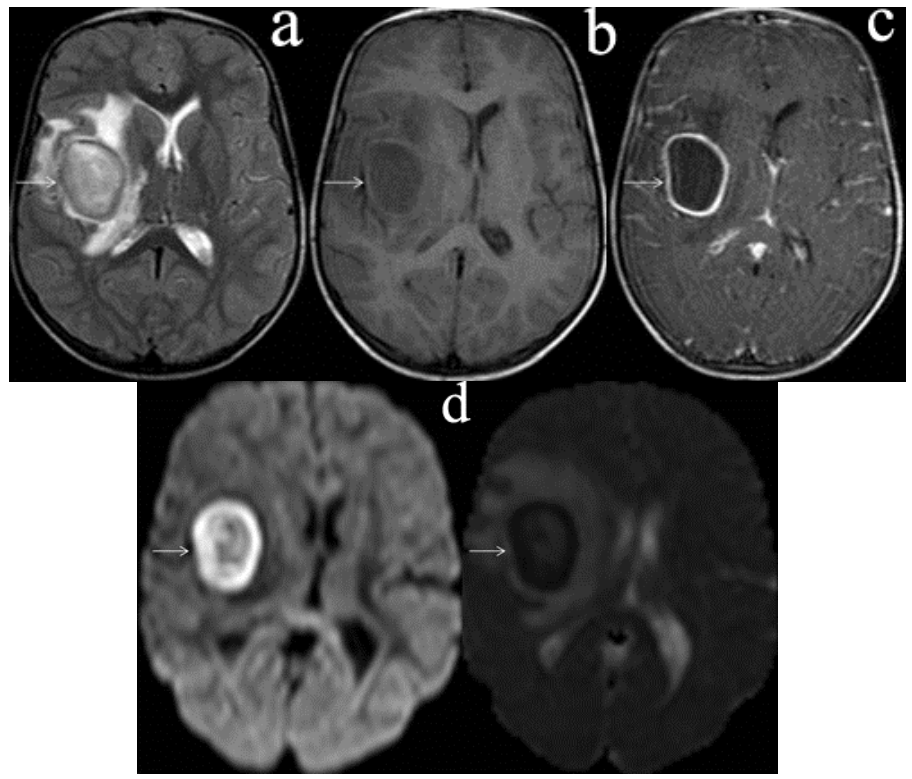

Fig. 8. Tubercular abscess. Axial T2W(a), T1W (b), and CEMR(c) images of another patient shows solitary ring enhancing lesions with liquified center, involving right basal ganglia region(arrow). There is associated marked perilesional edema with mass effect. The lesion demonstrates restriction on DWI and corresponding ADC mapping (d). MRS(not shown) revealed findings consistent with tubercular abscess.

\subsubsection{Miliary tuberculomas}

Miliary tuberculosis of the brain may be a part of generalized pathological process, with primary focus situated in the lung or elsewhere. The condition is subtle with no clinical evidence of brain involvement. On imaging, these lesions are small, less than $5 \mathrm{~mm}$ in size;

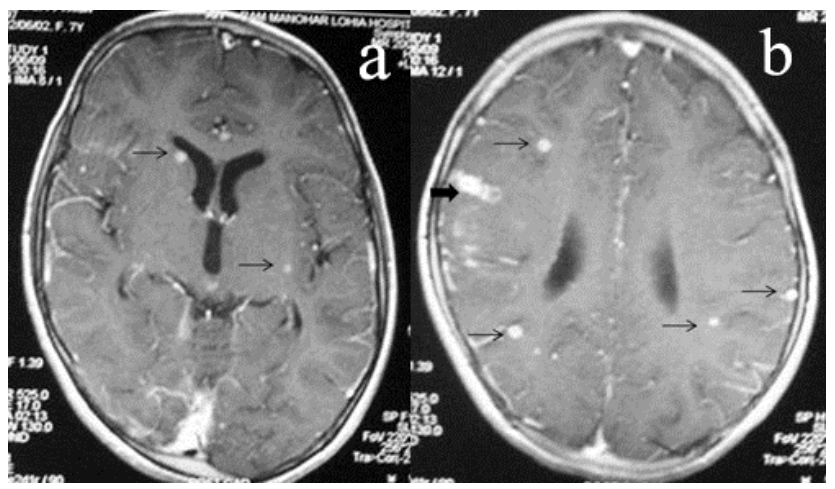

Fig. 9. Miliary tuberculosis. Post contrast T1W axial MR images of brain at two different levels reveal intense nodular enhancing small granulomas (thin arrow) randomly distributed throughout the brain parenchyma. Few larger lesions (thick arrow) were also seen along with these miliary nodules. 
located at cortico-medullary junction and in the distribution of perforating vessels. They appear as high signal intensity foci throughout the brain parenchyma on T2WI and show intense nodular enhancement on post gadolinium images [Figure 9]. Contrast enhanced MRI is more sensitive than CECT for detecting these lesions. ${ }^{41,42}$

\subsubsection{Focal tubercular cerebritis}

This entity was described by Jinskin based on retrospective analysis of five patients. CT imaging shows intense focal gyral enhancement. On MRI, focal tuberculous cerebritis appears hypointense on T1, hyperintense on $\mathrm{T} 2$ and shows small areas of patchy contrast enhancement on post gadolinium images. ${ }^{30}$

\subsubsection{Tubercular encephalopathy}

Tubercular encephalopathy is a diffuse cerebral disorder characterized by convulsion, stupor and coma, without signs of meningeal irritation or focal neurological deficit. It is exclusively seen in infants and children receiving antitubercular treatment. Imaging shows unilateral or bilaterally symmetrical cerebral white matter edema, occasionally with perivascular demyelination or hemorrhagic leukoencephalopathy. A picture resembling post-infectious demyelinating encephalomyelitis may be observed. The pathological basis suggested for TB encephalopathy is an allergic delayed type IV hypersensitivity reaction due to cell mediated immunity to tubercular protein. $.33,44$

\subsection{Tuberculoma en plaque}

An en plaque meningeal tuberculoma is a rare manifestation, seen as dural based, massforming localized meningeal process which morphologically resembles en plaque meningioma or meningeal metastases. They are commonly seen along the frontal and parietal convexities, tentorium, interhemispheric fissures and in the posterior fossa. On noncontrast CT, these lesions are hyperdense in appearance. On MRI, they appear isointense on T1WI, hypo to hyperintense on T2WI, and show homogenous or peripheral contrast enhancement, depending on the presence or absence of central caseation [Figure 10]. Prominent feeding meningeal vessels may also be evident. 45,46

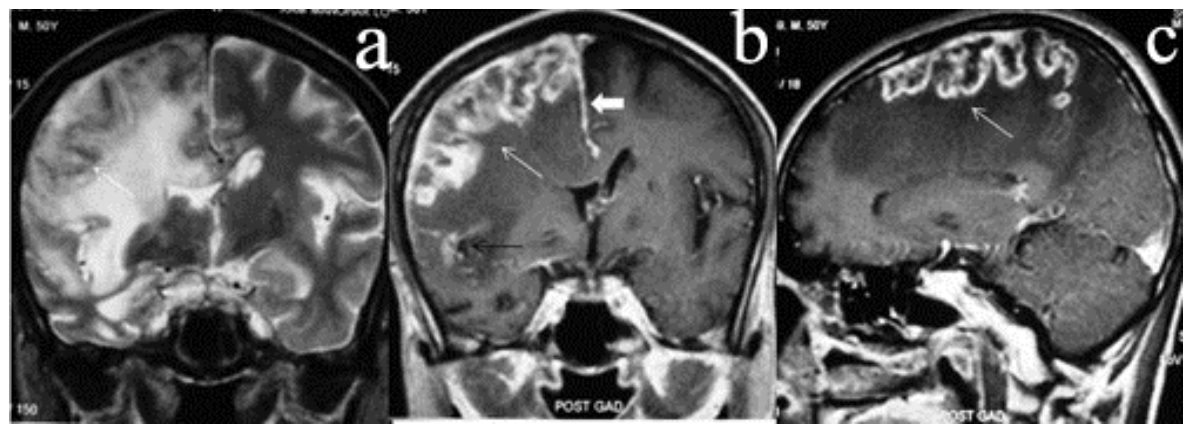

Fig. 10. En-plaque tuberculoma. T2W coronal image(a) shows predominantly hypointense dura based lesion widely spread along the right cerebral convexity, with associated marked vasogenic white matter edema and mass effect. Post contrast T1W coronal(b) and sagittal(c) image shows irregular peripheral rim enhancement of the lesion(thin white arrow). Also note, thickened enhancing dura along the falx (thick white arrow) and right cerebral convexity; and right sylvian fissure meningitis(thin black arrow). 


\subsection{CNS tuberculosis in AIDS}

Although TB infection of CNS in AIDS patients follows a rapidly progressive course, the spectrums of imaging findings are similar to those of the non-immunocompromised patients. Meningitis, cerebral abscesses and tuberculomas are often observed in combination with one another [Figure11]. The differential diagnosis includes other opportunistic infections and primary or secondary CNS lymphoma. ${ }^{47}$

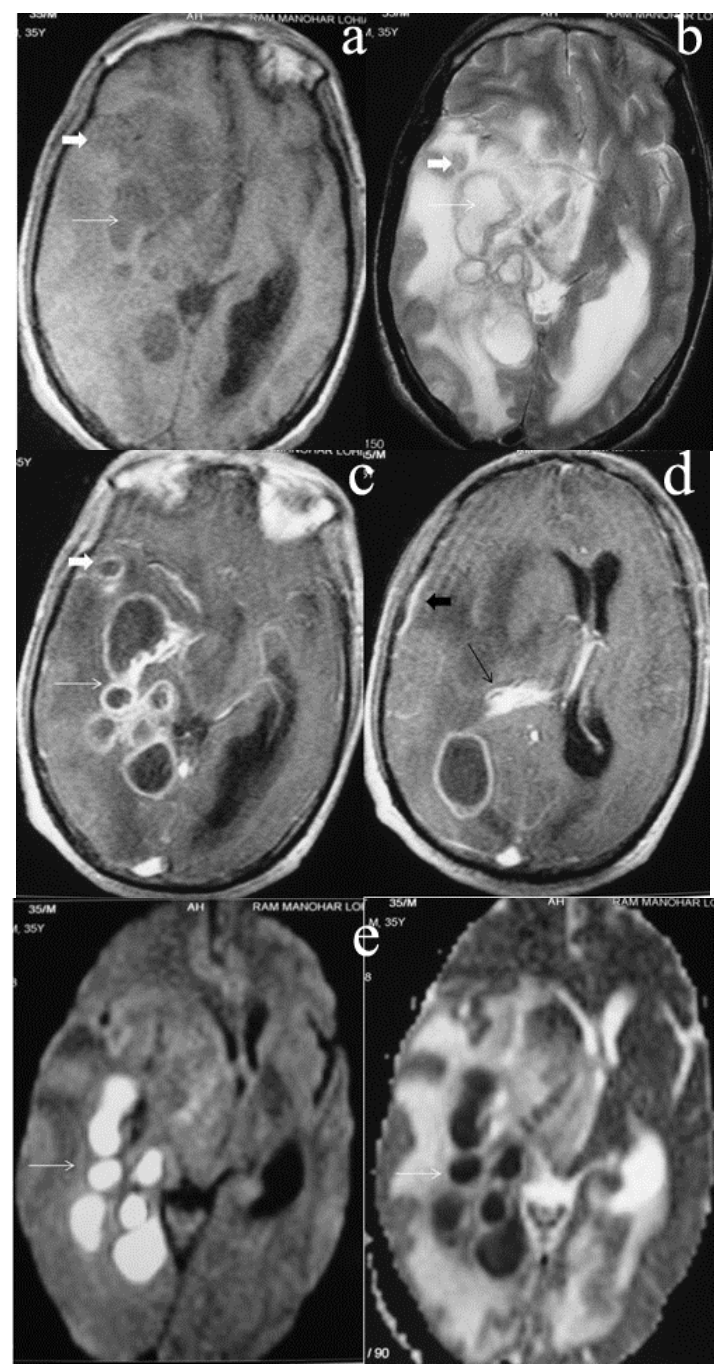

Fig. 11. CNS tuberculosis in AIDS. Axial T1W(a), T2W(b), post contrast(c) and diffusion weighted(d) MR images of brain demonstrate multiple cerebral abscesses (thin white arrows), tuberculomas(thick white arrow), choroid plexitis (thin black arrow) and dural thickening(thick black arrow). Note associated marked perilesional vasogenic edema with significant mass effect. 


\subsection{Tuberculous hypophysitis}

Tubercular hypophysitis is an extremely rare entity that commonly presents with enlargement of pituitary gland, mimicking a pituitary adenoma. On MR imaging, the gland is diffusely enlarged with a thickened stalk, seen infrequently. The thickening and enhancement of stalk and surrounding dura differentiates these lesions from pituitary adenoma[Figure12]. However, these are non-specific findings and are also seen with tuberculous meningitis, sarcoidosis, syphilis and eosinophilic granuloma. ${ }^{48}$

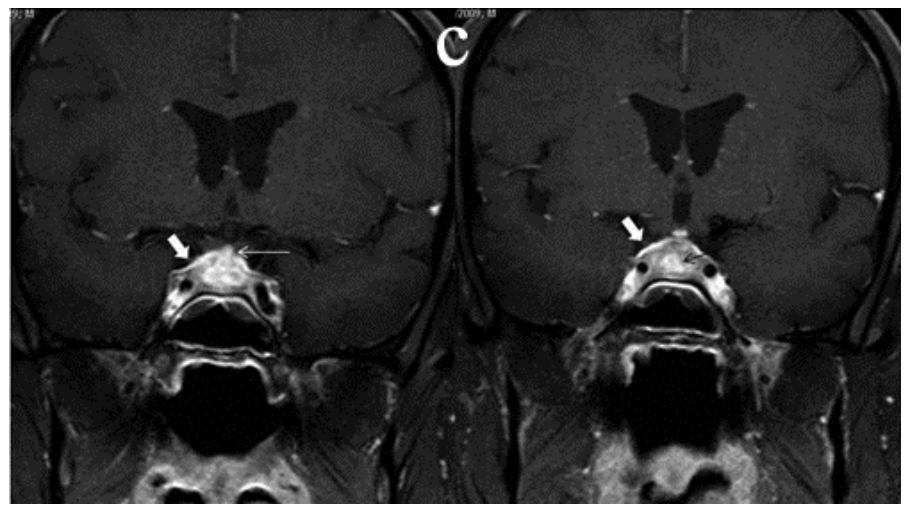

Fig. 12. Tuberculous hypophysitis. Post contrast T1W coronal MR images of a young adult male showing enlarged pituitary gland with intra-glandular ring enhancing tuberculoma (thin black arrow), and thick enhancing pituitary stalk(thin white arrow). Thickening and enhancement of diaphragma sellae (thick white arrow) is also noted. The patient had associated pulmonary tuberculosis and showed complete resolution of the pituitary lesion after a course of antitubercular therapy.

\subsection{Tuberculosis of calvarium and base of skull}

Isolated calvarial tuberculosis is a rare condition; and commonly occurs secondary to hematogenous spread from primary focus elsewhere. Frontal and parietal bones are most commonly involved followed by occipital and sphenoid bone. Calvarial tuberculosis may present as a subgaleal swelling (Pott's puffy tumor) with a discharging sinus when the outer table is involved. Inner table involvement which is relatively more common is associated with formation of underlying extradural granulation tissue. Both tables involvement is not uncommon. The bony lesions are usually osteolytic, and appear as a well defined punched out defect with central sequestrum. Rarely sclerosis may be seen. Cranial sutures do not prevent the spread of granulation tissue, and hence extensive destruction can occur before a sinus or swelling becomes apparent. Despite the dura mate, which is an effective barrier to the spread of infection, subdural empyema, meningitis, and parenchymal granulomas may be encountered. CT scan of the brain [Figure13] helps in assessing the extent of bone destruction, scalp swelling and extent of intracranial involvement. 49,50

Tuberculous ostitis of skull base (spheno-clival) is very rare in occurrence. The usual clinical picture is of jugular foramina syndrome. The involvement of skull base may be either by contiguous spread of infection from the adjacent site, or via hematogenous route from primary focus elsewhere. On imaging [Figure14], there is destruction of the skull base with enhancing soft tissue mass that may cause compression of adjacent structures. Associated 


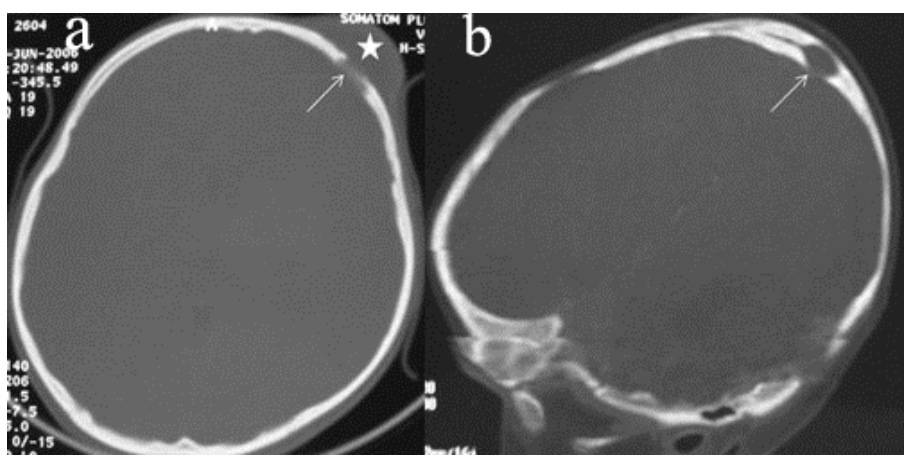

Fig. 13. Calvarial tuberculosis. NCCT head (bone window) of two different patients. First case(a) shows a large subgaleal soft tissue swelling (Pott's puffy tumor)(asterix) with destruction of both outer and inner table(arrow). Second case(b) shows a well defined lytic lesion involving right parietal bone with destruction of inner table but intact outer table(arrow). Both the cases showed no intracranial extension of the lesion.

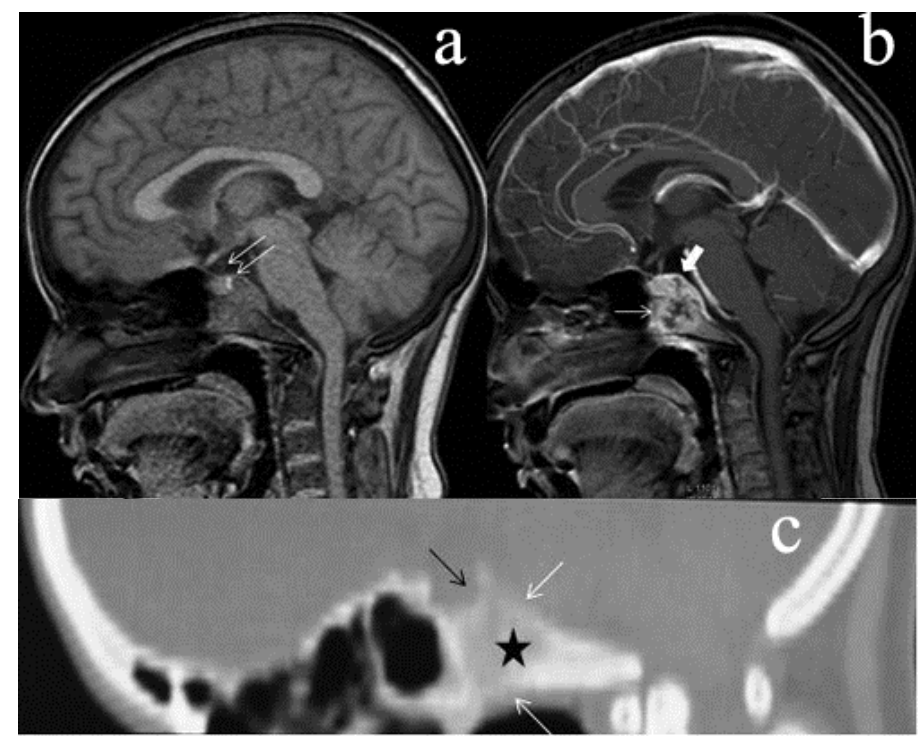

Fig. 14. Spheno-clival tuberculosis. Sagittal plain (a) and post contrast(b) T1W MR image of brain demonstrates an intraosseous soft tissue lesion in anterior part of body of clivus, showing heterogeneous contrast enhancement(thin white arrow). The dura along the superior aspect of the clivus shows thickening and enhancement(thick white arrow). Soft tissue along the inferior margin of the clivus also shows inflammatory changes. Note, the pituitary gland and the stalk(double white arrow) which appears normal in morphology and signal intensity. Sagittal NCCT skull(c) demonstrates destruction of anterior half of the body of clivus(asterix) and erosion of both antero-superior and antero-inferior cortical margin of the clivus(thin white arrow). The floor of sella tursica and the posterior clinoid process also shows rarefaction (thin black arrow). 
meningitis may further complicate the disease producing multiple cranial neuropathies. The imaging characteristic mimics a malignant tumor (e.g. Cordoma), making the diagnosis of tuberculosis difficult, hence a high degree of clinical suspicion is mandatory. ${ }^{51,52}$

\subsection{Orbital tuberculosis}

Tuberculosis of orbit is rare, usually occurring in pediatric age group. Hematogenous spread from a primary tubercular focus or contiguous spread from paranasal sinuses may affect the orbit. The disease is usually unilateral and has slow progressive course. The imaging findings include involvement of bony orbital wall (producing cortical irregularity, destruction, thickening or sclerosis) and lacrimal gland, with extraconal inflammatory mass or frank abscess formation. The patient may present with isolated preseptal thickening. Infratemporal and intracranial extension is not uncommon [Figure15]. MRI is the imaging modality of choice in these cases. Post contrast, fat suppression techniques significantly

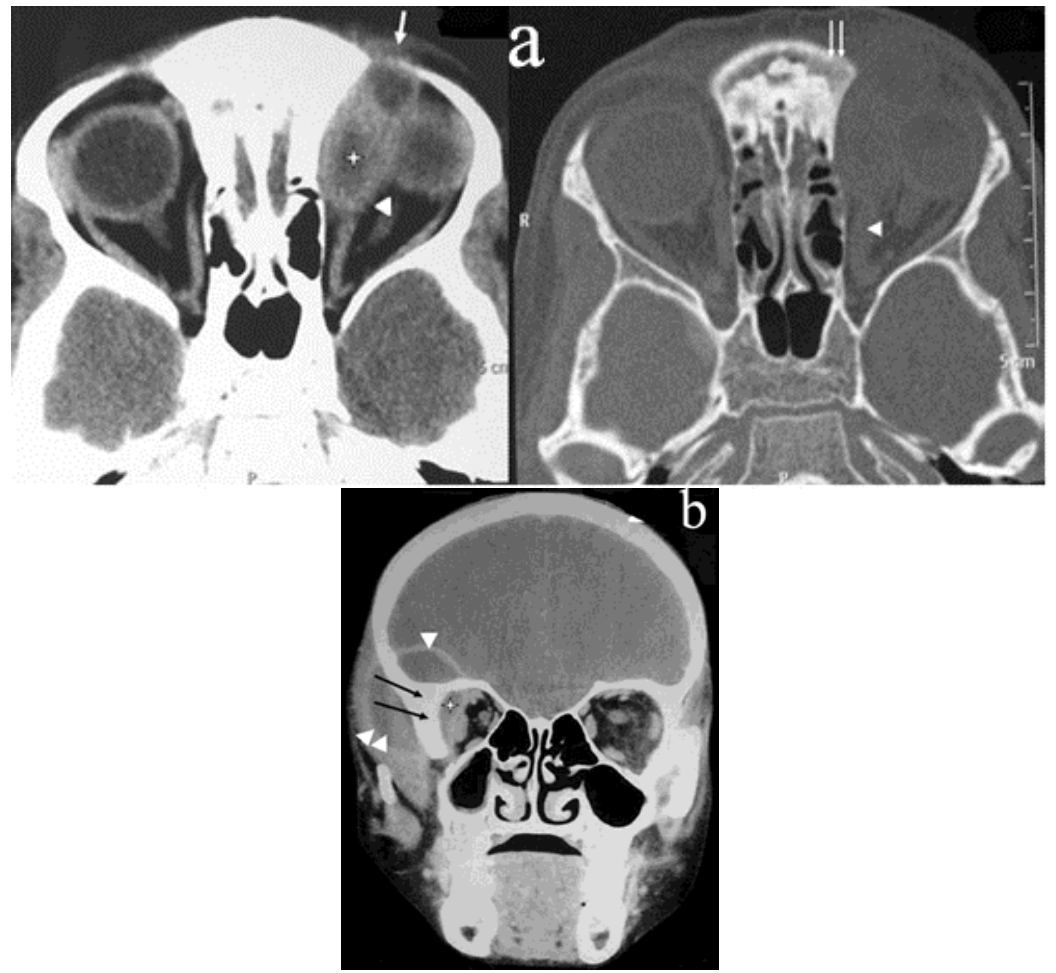

Fig. 15. Orbital tuberculosis. Axial CECT orbit(a) shows a medially situated extraconal orbital abscess(asterix) with extension into preseptal tissue and root of nasion(single thin arrow). Adjacent medial rectal muscle is displaced medially by the extraconal mass(arrow head). Irregularity and destruction of nasion(double thin arrows) is also present. Coronal CECT orbit (b) of another patient shows a laterally situated extraconal lacrimal gland abscess(asterix) which extends intracranially as epidural abscess(single arrow head) and into the infratemporal fossa (double arrow heads). Ipsilateral zygomatic bone appears thickened (double black arrows). (From IJRI 2010; 20:6-10. 
improve the visualization of subtle masses. Non-tuberculous infection, vascular malformations and various neoplasms should always be considered in differential diagnosis of orbital masses. 53

\subsection{Tubercular otitis media and tuberculosis of temporal bone}

Tubercular otitis media (TOM), a relatively uncommon condition, may be a part of widespread central nervous system disease or hematogenous spread from a primary tubercular focus elsewhere. The disease is more common in infants and children. It may be unilateral or bilateral. The patient usually presents with profuse painless otorrhea. High resolution $\mathrm{CT}$ is the modality of choice for imaging the temporal bone. Imaging shows middle ear soft tissue mass with destruction of bony walls. In addition, mucosal thickening of bony external auditory canal (EAC), extension of soft tissue mass into EAC and destruction of osscicles may also be documented. However, the scutum is always preserved in a case of TOM. T1-weighted post gadolinium MR images demonstrate the extent of inflammatory changes, evident as enhancing granulation tissues. Important complications include conductive deafness, facial palsy, cochlear involvement with labyrinthitis, sensory neural hearing loss and intracranial dissemination of infection. Mastoiditis and sinus formation may occur. Important differential includes other bacterial infections, cholesteatoma, fungal granulomas, wegener's granulomatosis, Langerhans cell histiocytosis. ${ }^{5}$

\subsection{Spinal tuberculosis}

\subsubsection{Tuberculous Spondylitis (pott's spine)}

Tuberculous Spondylitis is a leading cause of paraplegia. In developing countries, spinal tuberculosis affects younger age groups, including infants and children. In developed countries, it mostly affects the elderly. However, due to HIV epidemic, its incidence has increased among younger age groups. The disease has insidious onset and indolent course. The lower dorsal and lumbar spines are most commonly affected, followed by cervical spine. The atlanto-axial region involvement is relatively uncommon. The disease process results from hematogenous spread of infection to the vertebral body via paravertebral venous plexus of Batson. Infection usually begins in anterior part of vertebral body within the cancellous bone adjacent to the end plate or anteriorly under the periosteum of the vertebral body. Destruction of end plate allows the spread of infection to the adjacent intervertebral disc, and subsequently to the additional spinal segment. Subsequent spread of infection to other vertebral bodies may also occur via subligamentous route, with sparing of intervertebral disc [Figure16]. Thus the classic pattern of involvement of more than one vertebral body together with the intervening disc is seen in TB spine [Figure17]. Skip lesions are not uncommon. Occasionally, tuberculous spondylitis affects only one vertebral body, sparing the adjacent disc. The pedicle and posterior element involvement is rare. The spread of infection into the paraspinal tissues results in the formation of paravertebral soft tissue inflammatory mass (phlegmon) and/or frank abscess [Figure16,17]. Intraspinal extension is also frequent. 55,56,57,58 Neurological deficits are commonly associated with spinal tuberculosis of cervical region, particularly when cranio-vertebral junction or C1-C2 spine is involved [Figure18]. The neurological deficit is usually caused by significant thecal or cord compression by displaced bony fragment, epidural inflammatory mass and/or abscess. Death may occur due to atlanto-axial instability or cervico medullary compression. 59,60 


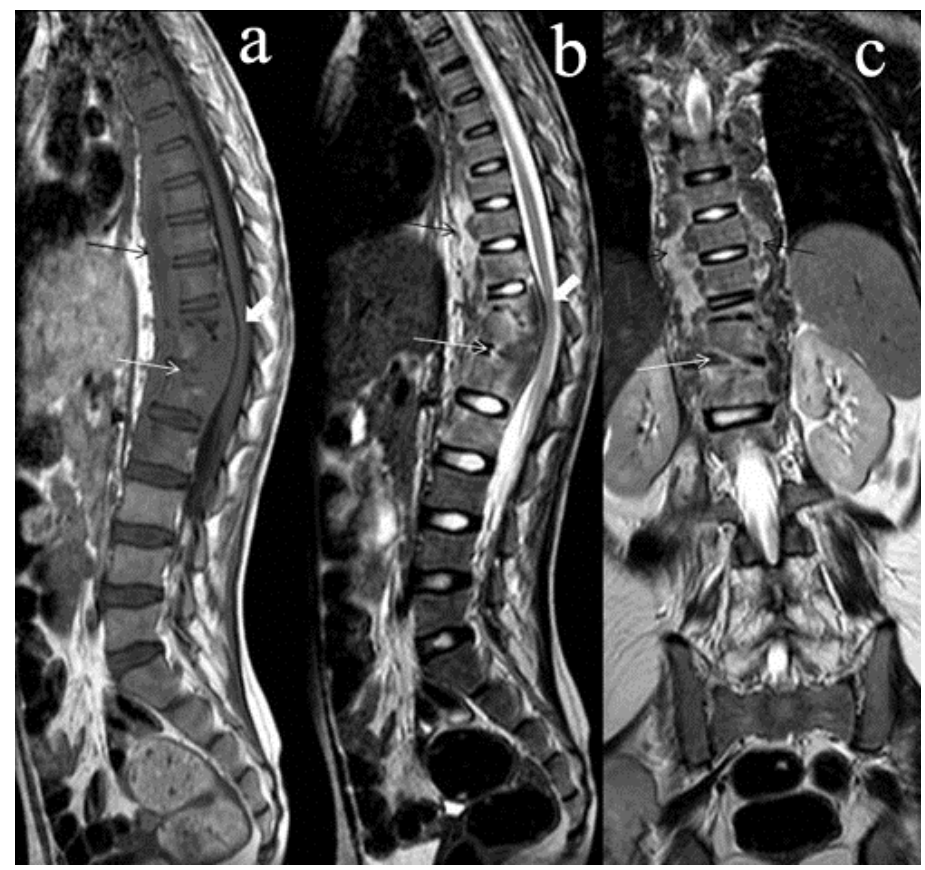

Fig. 16. Tuberculous spondylitis (Pott's spine) with subligamentous spread of the disease. Sagittal T1W(a), T2W(b), and Coronal T2W(c) image of dorso-lumbar spine demonstrates primary involvement of D12-L1 vertebral bodies and the intervening discs (thin white arrow) by the disease process with contiguous spread if the infection cranially (to involve all dorsal vertebrae) and caudally(to involve L2 vertebra) along the subligamentous route(thin black arrow) with sparing of intervening discs(except at D12-L1 level). Note, marrow signal intensity changes in all the involved vertebral bodies, and an epidural phlegmon at D12-L1 level causing localized cord compression (thick white arrow).

Conventional radiograph of spine demonstrates end plate irregularity, destruction of vertebral body and involvement of intervertebral disc. Reactive sclerosis is not a feature on initial presentation. CT scans [Figure19] characteristically demonstrate extensive bone destruction and large paraspinal abscesses. Large paravertebral abscesses and subligamentous spread of infection may produce anterior scalloping of the vertebral bodies. Calcification within the abscess is virtually diagnostic for tuberculosis. If left untreated, the infection eventually results in vertebral collapse and anterior wedging, leading to kyphosis and gibbus formation with healing, fusion of vertebral bodies (bony ankylosis) occurs in most cases. In patients with neurological deficit CT can define the extent of epidural compression, detection of bony fragment within the spinal canal and atlanto-axial instability. ${ }^{61,62} \mathrm{MRI}$ is the modality of choice for evaluating intraspinal and subligamentous spread of the infection, cervico medullary junction and nerve root compression, intervertebral disc changes and vertebral skip lesions. Contrast enhanced MRI is particularly useful for demonstrating intraosseous, epidural and paraspinal soft tissue involvement. $56,57,58$ 

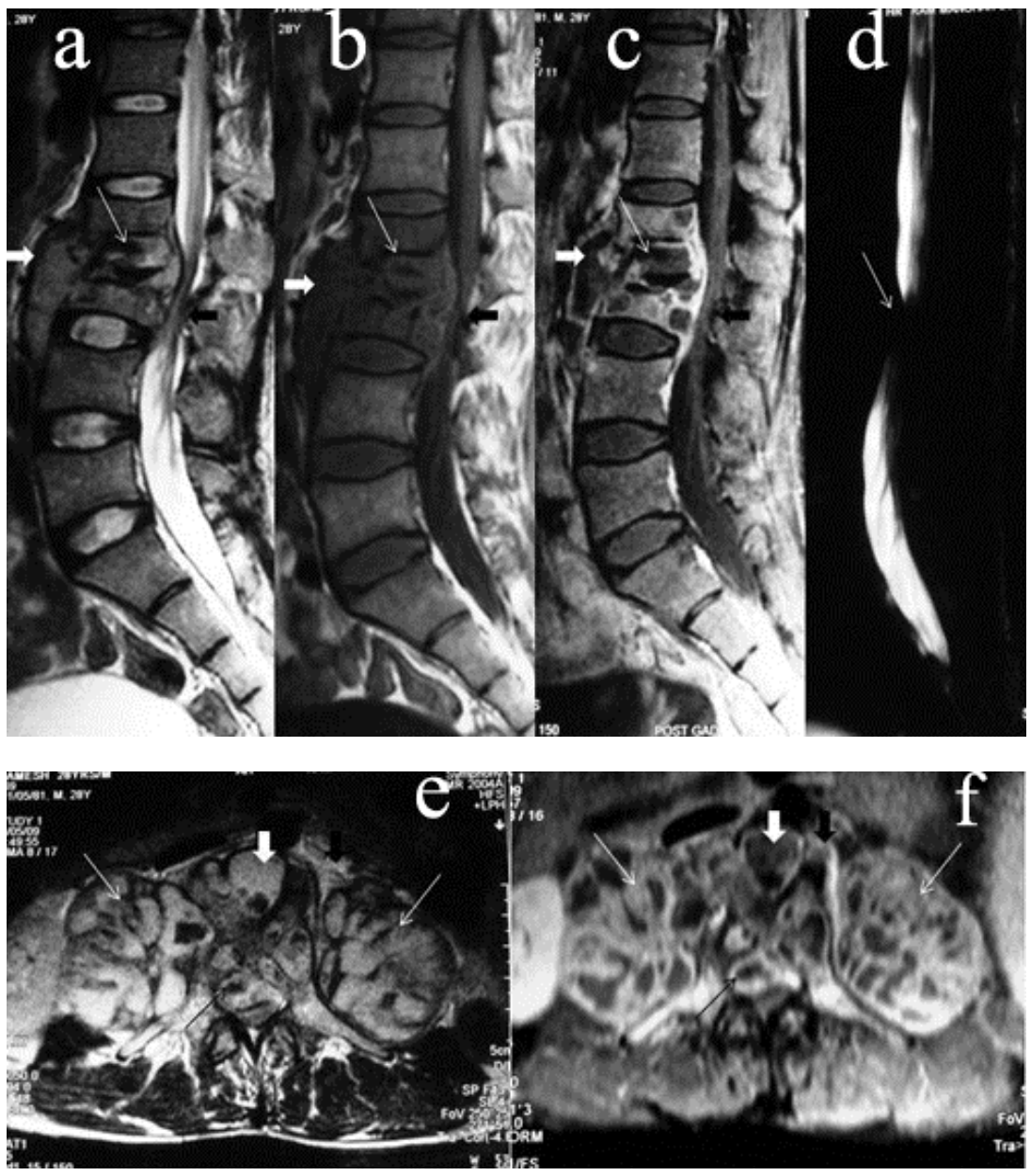

Fig. 17. Tuberculous spondylitis with involvement of intervening disc. Sagittal T2W(a), $\mathrm{T} 1 \mathrm{~W}(\mathrm{~b})$ and post contrast(c) MR of lumbar spine demonstrates involvement of L2-L3 vertebral bodies and the intervening discs by the disease process, showing osseous destruction and heterogeneous contrast enhancement(thin white arrow). Associated heterogeneous enhancing prevertebral soft tissue(thick white arrow) and an epidural phlegmon/abscess(thick black arrow) is also present at the same level. The epidural phlegmon/abscess causes severe lumbar canal stenosis and compression of conus and cauda equina nerve roots, producing a CSF cut off sign on MR myelogram (d) (thin white arrow). Multiple intraosseous lesions (thick white arrow), subligamentous inflammatory mass(thick black arrow), bilateral psoas abscesses (thin white arrow) and epidural phlegmon causing cord compression (thin black arrow) are well appreciated on axial T2W(e) and T1W post contrast image(f). 


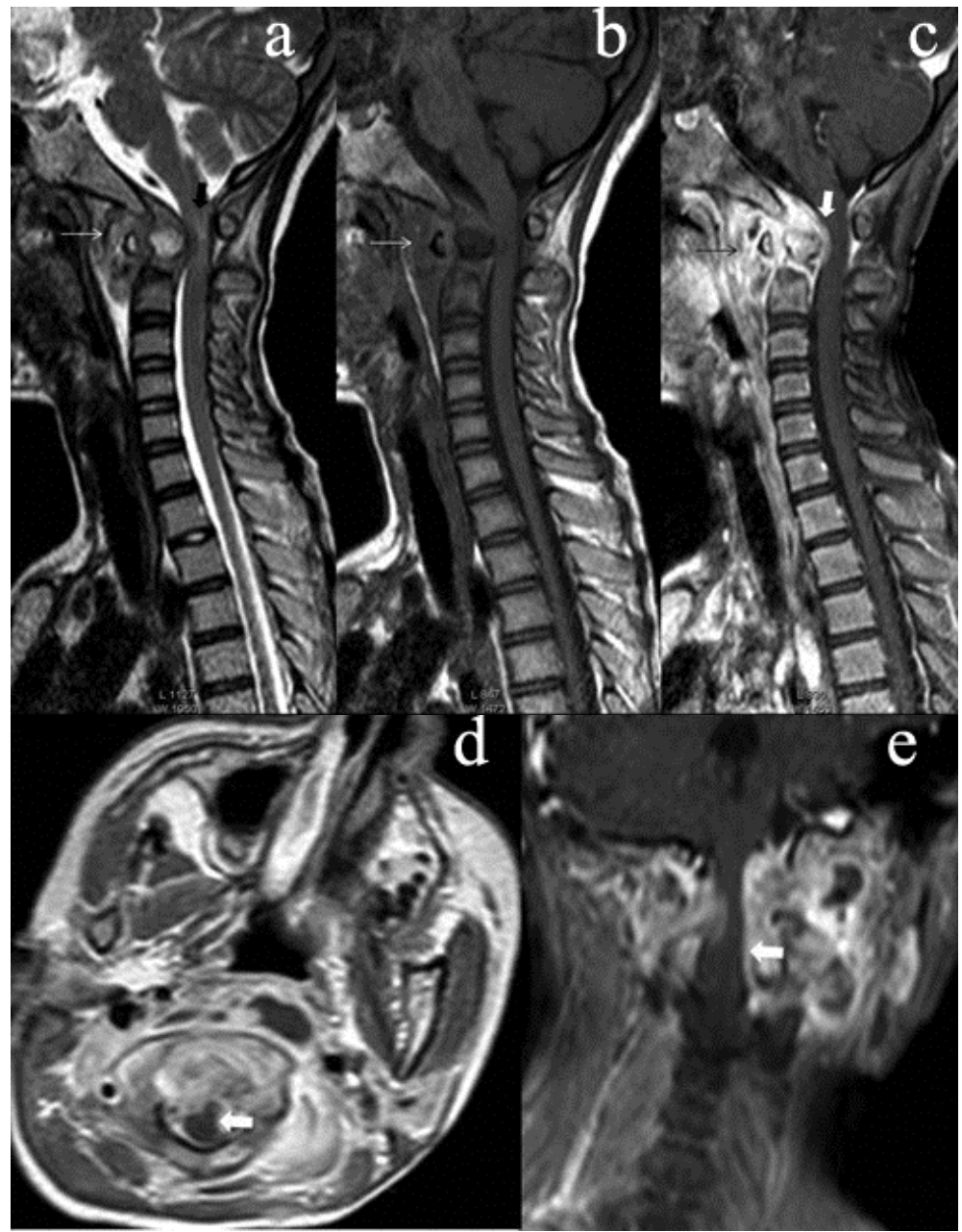

Fig. 18. Tuberculous spondylitis (C1-C2 vertebrae). Sagittal T2W(a), T1W(b) and post contrast(c) image of cervical spine shows enhancing inflammatory soft tissue mass (thin arrows) surrounding the anterior arch of C1 vertebra, tip of odontoid process (os odontoideum) and posterior part of the clivus, appearing isointense to the cord both on T1W and $\mathrm{T} 2 \mathrm{~W}$ image. Note subligamentous spread of infection along anterior aspect of $\mathrm{C} 2-\mathrm{C} 3$ vertebral body. There is associated atlanto-axial dislocation and cervicomedullary junction compression both by the posteriorly displaced odontoid tip and epidural-intraspinal phlegmonatous inflammatory tissue (thick white arrow), best appreciated on post contrast sagittal(c), axial(d) and coronal(e) images. The compressed cervical cord shows focal T2 hyperintense(thick black) signal suggestive of compressive myelopathy. Intraosseous marrow signal changes involving anterior arch of atlas, odontoid tip and posterior part of clivus is also present. There is severe narrowing of nasopharynx and the oropharynx by the prevertebral inflammatory mass. 


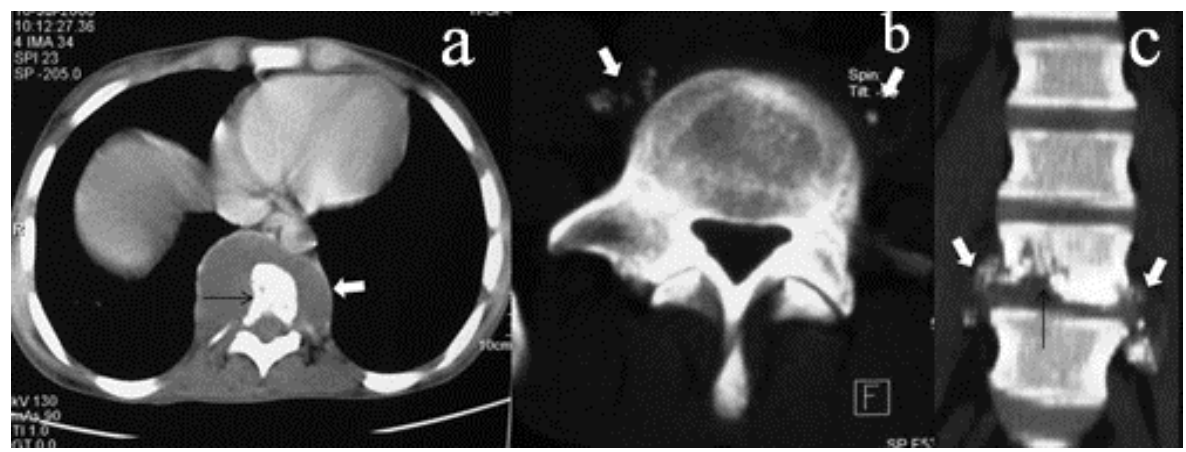

Fig. 19. Tuberculous spondylitis (Pott's spine). Axial (a,b) and coronal (c) noncontrast CT spine demonstrates marked osseous and intervertebral disc destruction(thin black arrow), and calcified/ non-calcified paravertebral abscesses(thick white arrows).

The major differential diagnosis is low grade pyogenic osteomyelitis (e.g. brucellosis), metastatic disease and fungal infections. Tuberculosis is characteristically associated with little or no reactive sclerosis, a feature that helps to distinguish it from pyogenic infections of spine. ${ }^{58}$ Tuberculosis rarely affects the posterior vertebral elements, including pedicles, in contrast to metastatic disease. ${ }^{62}$ Anterior scalloping of vertebral bodies can also be seen with paravertebral lymphadenopthy, metastatic or lymphomatous deposits. ${ }^{58,62} \mathrm{CT}$ guided needle biopsy is very useful in establishing the diagnosis in case of uncertainty.

\subsubsection{Non-osseous spinal tuberculomas}

Spinal tuberculoma are very rare presentation of non-osseous spinal tuberculosis, characterized as extradural (64\%), intramedullary $(8 \%)$, or intradural extramedullary (IDEM) (1\%) according to their location.63 Most of the subdural (IDEM) tuberculomas are detected as a result of paradoxical response to antitubercular therapy for meningitis, ranging from three months to one year. ${ }^{64}$ Intramedullary tuberculomas are mostly induced by hematogenous dissemination from primary focus in the lung, or via CSF seeding, and rarely local spread of spinal tuberculosis. ${ }^{65}$ MRI is imaging modality of choice for these lesions. IDEM tuberculoma may present as a single, dural based ring enhancing lesion or as a long segment enhancing soft tissue mass. En plaque IDEM tuberculoma may mimic meningioma. IDEM tuberculomas commonly cause spinal cord and nerve root compression; however, may or may not be associated with arachnoiditis [figure20].64,66 Concurrent IDEM tuberculoma and syringomyelia has also been reported. ${ }^{67}$ Intramedullary tuberculomas have specific findings on MRI, and hence can be diagnosed accurately on imaging. T2WI shows a typical "target sign" demonstrating low signal center (caseous material) surrounded by high signal rim (peripheral infective granulation tissue). This "target sign" is a valuable indicator and differentiates tuberculoma from other intramedullary lesions. Intravenous contrast administration shows sharp margin with peripheral rim enhancement. Associated syrinx and/or arachnoiditis may or may not be present with these lesions [Figure21]. 65 


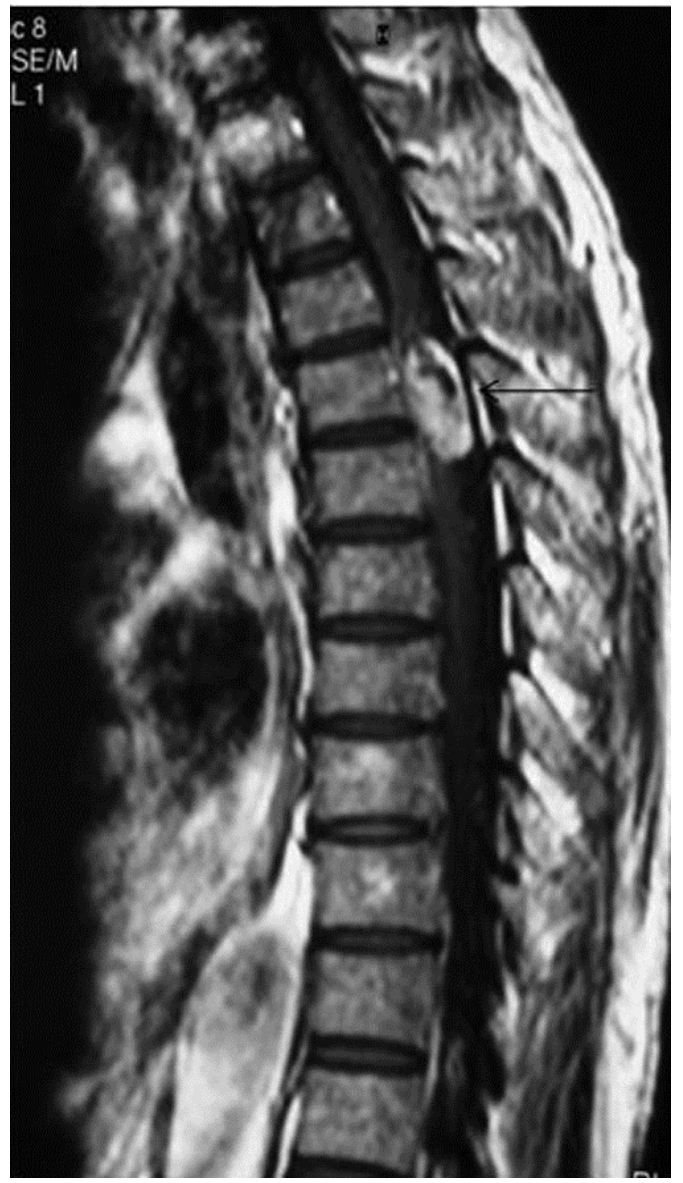

Fig. 20. Intradural extramedullary spinal tuberculoma. Contrast enhanced T1-weighted Sagittal image demonstrates an intradural extramedullary (arrow) lesion in posterior subarachnoid space, at mid-dorsal spine level, showing dense nodular enhancement with a linear non-enhancing area. There is localized spinal cord compression and widening of dorsal subarachnoid space. No associated syrinx or arachnoiditis is present. 

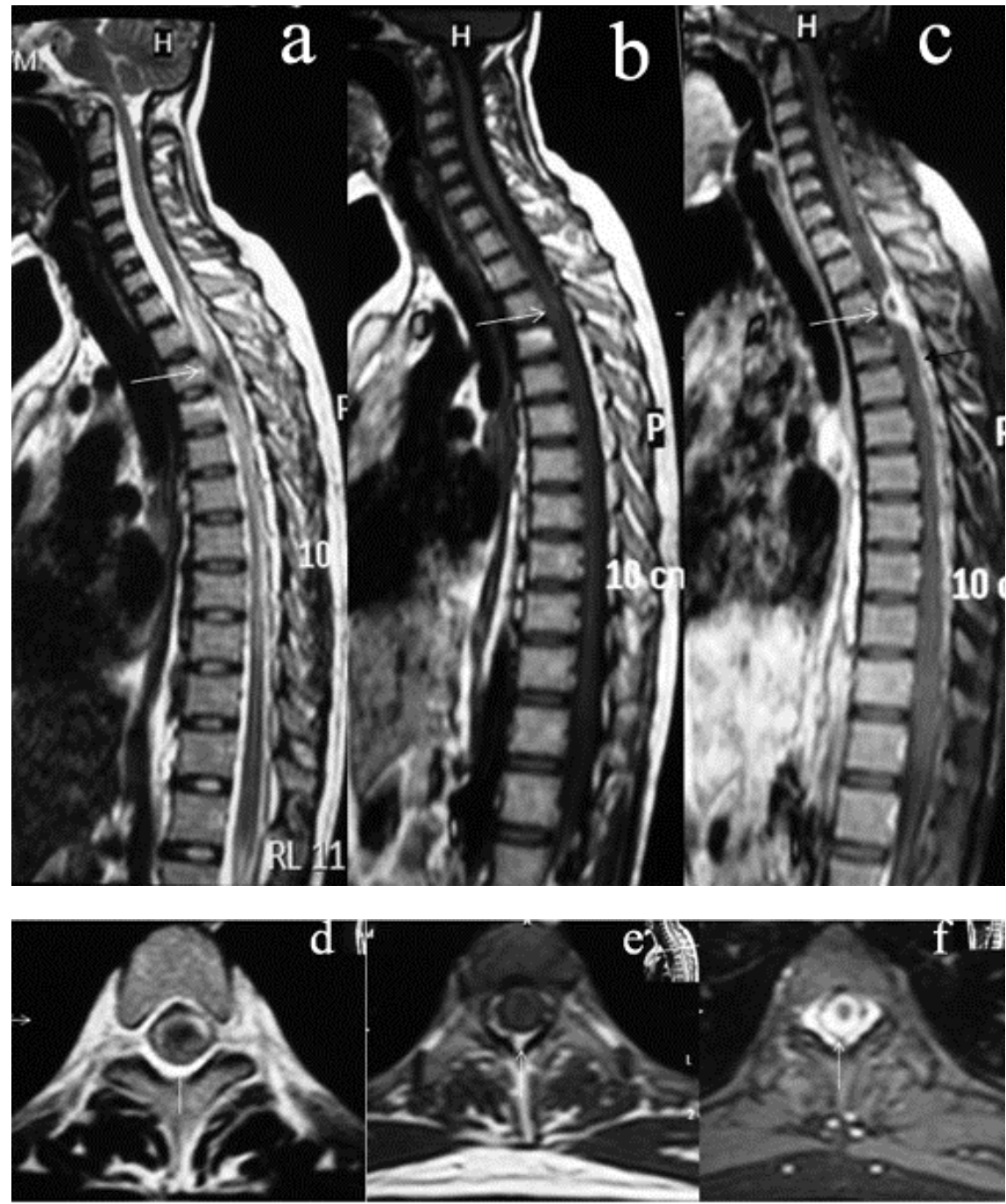

Fig. 21. Intramedullary tuberculoma with arachnoiditis. Sagittal T2W(a), T1W(b) and post contrast(c) image of thoracic spine shows an intramedullary space occupying lesion (thin white arrow) at D3 level with loss of normal cord-CSF interface posteriorly from D1-D11 level and few thin septations within posterior subarachnoid space, best appreciated on $\mathrm{T} 2 \mathrm{~W}$ image. The intramedullary SOL appears iso-hypointense on T1W image, shows typical "target sign" on T2W image and peripheral rim enhancement on contrast administration. There is obliteration and intense enhancement of posterior subarachnoid space from D1-D11 level with scattered thin CSF loculations consistent with arachnoiditis (thin black arrow). Note, a short segment syrinx situated cranial to the intramedullary lesion and T2 hyperintense signal within the cord caudal to this lesion. Intramedullary tuberculoma is well appreciated on axial T2W(d), T1W(e) and post contrast(f) images. 


\subsubsection{Spinal tubercular arachnoiditis (myeloradiculopathy)}

Spinal tuberculous arachnoiditis is an inflammatory condition that involves the leptomeninges along the spinal tract and often manifests as myeloradiculopathy. Previously, it was known as adhesive spinal arachnoiditis or chronic adhesive arachnoiditis. Clinically patient presents with progressive spinal cord and/or nerve root dysfunction, usually accompanied by constitutional symptoms. This condition may result from downward extension of intracranial tuberculous meningitis (most common) or a tuberculous lesion primarily arising in the spinal meninges, or extension from tuberculous spondylitis. The thoracic region is most commonly affected followed by the lumber and cervical region. The involvement may be focal, multifocal or diffuse. The inflammatory exudate surrounds the spinal cord and the nerve roots, causing obliteration of spinal subarachnoid space (SAS). On imaging [figure22], there is increased CSF signal intensity within the SAS on T1WI due to elevated protein content of CSF with resultant loss of spinal cord outline in cervico-thoracic region. Thickening and clumping of nerve roots in the lumber region is frequently seen with arachnoiditis. Meningeal involvement has been described in patients with arachnoiditis; it represents ongoing meningeal inflammation and may constitute an early sign of arachnoiditis. Contrast enhanced MR images show linear enhancement of surface of spinal cord and nerve roots, or plaque like enhancement of dura-arachnoid mater complex which can obliterate the subarachnoid space. ${ }^{68}$ Enhancing subarachnoid space nodular lesions may represents IDEM tuberculoma or vascularized fibrous tissue. In chronic adhesive

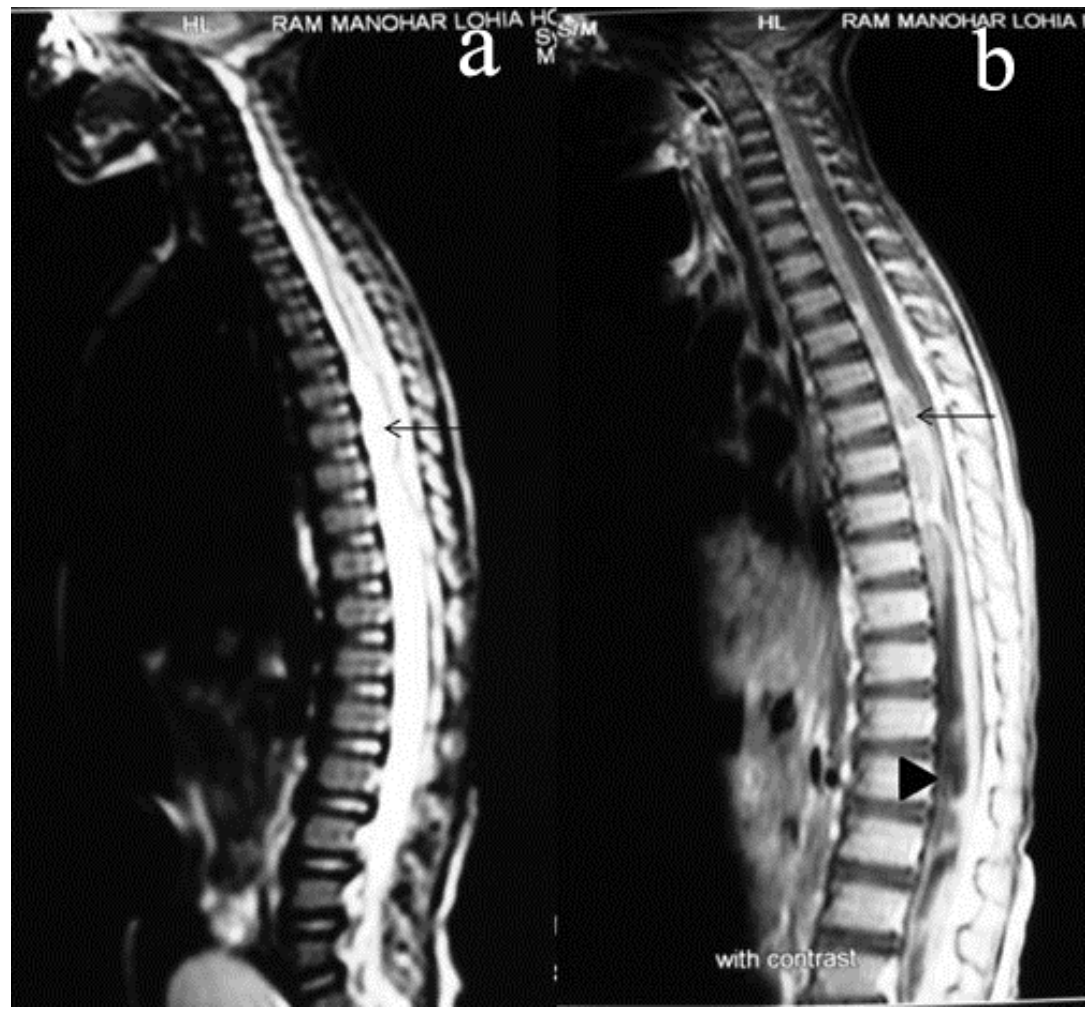




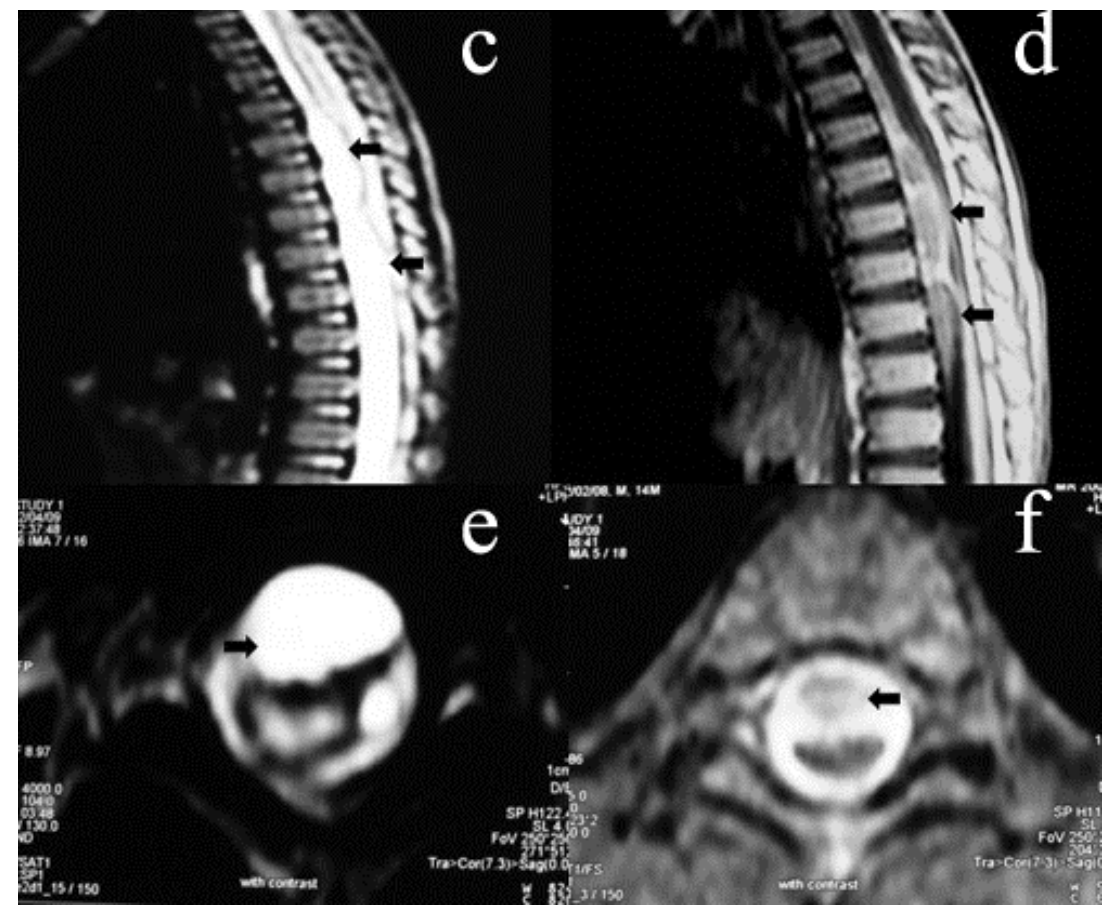

Fig. 22. Tuberculous spinal arachnoiditis with ascending infection to the brain. Sagittal T2W (a) and T1W post contrast(b) MR image of whole spine demonstrates loss of normal cord-CSF interface with obliteration of anterior subarachnoid space(SAS) by thick inflammatory exudates appearing hyperintense on T2W image, and showing intense enhancement on post contrast image (thin black arrow). Few scattered intervening septae are also present within the anterior SAS (at upper cervical and mid thoracic level) forming loculations. These loculations containing the inflammatory tissue have pseudomass appearance (on sagittal and axial T2W/post contrast image-c,d,e,f), which causes severe cord compression (thick black (arrow). Thickening and clumping of cauda equine nerve roots is evident in lumbar region (arrow head). The obliteration and intense enhancement of anterior subarachnoid space along the entire spinal canal, scattered pseudomasses in upper cervical (please see figure5b-sagittal post gad. image) and mid thoracic level, and clumping of cauda equine nerve roots in lumbar region is consistent with spinal arachnoiditis.

arachnoiditis, the spinal SAS is irregularly obstructed with formation of CSF loculations. ${ }^{32}$ The CSF loculations usually show normal CSF signal intensity on T1-and T2WI and do not enhance on post contrast images. The recognition of CSF loculation is important as they may cause cord compression, necessitating surgical intervention. The spinal cord changes are frequently seen in these patients and may include myelitis, cord edema, syringomyelia, infarction, myelomalacia, cavitation or atrophy. ${ }^{32}$

Spinal tuberculous arachnoiditis must be distinguished from other possible causes of arachnoiditis, for example subarachnoid hemorrhage or iatrogenic cause. 


\subsubsection{Tubercular myelitis}

Tuberculous myelitis, an important cause of paraparesis, and usually occurs as a secondary event in the course of common forms of tuberculous meningitis. The cervico-thoracic segment of the spinal cord is most commonly involved. MR Imaging features of TB myelitis are similar to those of cerebritis. There is diffuse cord swelling with signal abnormality. Most spinal cord lesions appear as hyperintense on T2, isointense to hypointense on T1weighted images, and show segmental enhancement on post contrast images [Figure23].

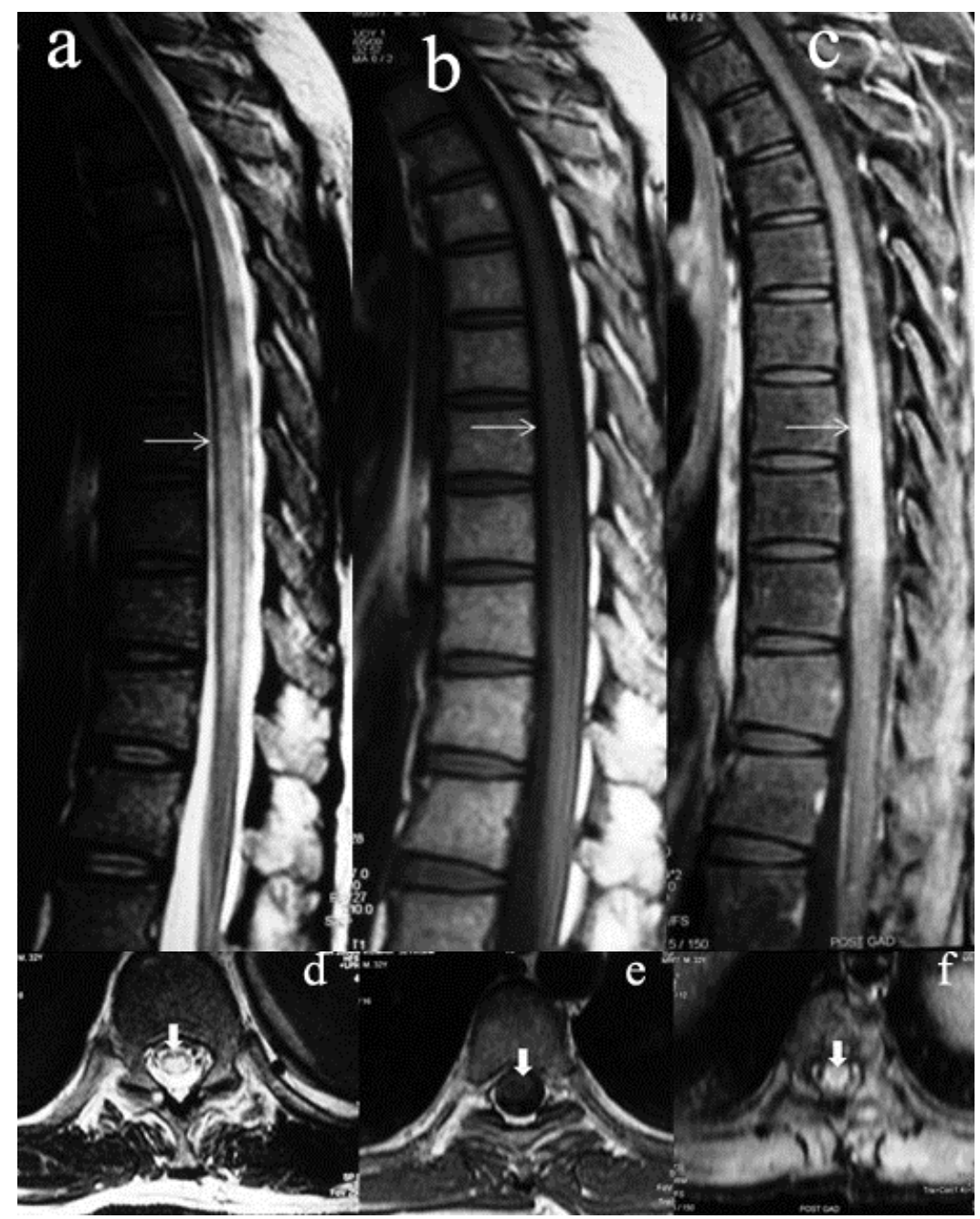

Fig. 23. Tuberculous Myelitis. Sagittal T2W(a), T1W(b) and post contrast(c) MRI of dorsolumbar spine shows diffuse cord swelling and edema appearing hypointense on T1W and hyperintense on $\mathrm{T} 2 \mathrm{~W}$ image and showing intense central contrast enhancement on post gadolinium images(thin white arrow). These changes are better appreciated (thick white arrow) on axial T2W(d), T1W(e) and post contrast image(f). 
Intramedullary abscess demonstrates central necrotic area with clearly defined marginal enhancement. Cord atrophy, cavitation and syringomyelia may be associated with poor outcome. Differential diagnosis includes cord contusion, cord infarction due to vasculitis, acute transverse myelitis, and demyelinating diseases. 69,70

\section{Differential diagnosis}

The important differential diagnosis of CNS tuberculosis has been already discussed with individual manifestations. Broadly, the conditions which may mimic cranial and spinal tuberculosis on imaging include other infectious and non-infectious inflammatory disease such as fungal infection, sarcoidosis, primary and metastatic neoplastic disease.

\section{Role of imaging in the evaluation of cns tuberculosis}

Role of imaging has been dealt in detail with individual manifestation of CNS tuberculosis (vide supra). In nut shell contrast-enhanced MRI is superior to CT scanning or unenhanced MRI for the demonstration of CNS TB, and is currently the best modality for demonstration of meningeal disease, parenchymal abnormalities, for assessment of complication and monitoring the disease. The multiplanar capability of MRI offers additional advantage for localization of lesions. CT is particularly used for evaluation of osseous changes, calcification, and intracranial shunt in cases of hydrocephalus.

\section{Management of cns tuberculosis}

Inspite of rapid advances in the management of pulmonary tuberculosis, currently no general agreement about the form of chemotherapy or optimal duration of treatment has been reached. The World Health Organization ${ }^{71}$ has put CNS tuberculosis under TB treatment category1, and recommended an initial phase therapy with streptomycin, isoniazid, rifampicin and pyrazinamide for 2-months, followed by a seven month continuation phase with isoniazid and rifampicin. The duration of therapy should be at least 6-months, and in some cases up to 12-months treatment is required. A similar drug regimen has been recommended for all forms of CNS tuberculosis. A four-drug regimen is needed to treat atypical mycobacteria (M avium intracellulare) in persons with HIV infection. Current recommended therapy for HIV patients include azithromycin and clarithromycin in combination with ethambutol or clofazimine. ${ }^{72,73,74}$

Role of corticosteroids in the treatment of CNS tuberculosis is controversial. It is believed that corticosteroids improve both the survival rate and neurological outcome in patients with TB meningitis. However they should be used with caution in pediatric population. The response to corticosteroids may be dramatic with rapid resolution of basal exudates and tuberculomas on serial imaging. The main argument against using corticosteroids is that they decrease meningeal inflammation, and in turn can affect CSF penetration of antituberculous drugs. ${ }^{74,75}$

Surgical procedures in patients with tuberculous meningitis are primarily directed to the treatment of hydrocephalus. Serial lumbar puncture along with diuretics is used as temporary measures to relieve raised intracranial pressure. Ventriculo-peritoneal or ventriculo-atrial shunts are permanent measures, which relieve the signs and symptoms of hydrocephalus and significantly improve the sensorium and neurological deficit. However, 
these shunts may require replacement due to blockage by high protein content of CSF. Early shunting in combination with drug therapy offers best therapeutic outcome.

Intracranial tuberculoma, which may behave as single space occupying lesion causing midline shift and increased intracranial pressure, and that fail to respond to chemotherapy should be removed surgically.72,76 In chronic adhesive spinal arachnoiditis, the CSF loculations in SAS may cause cord compression, necessitating surgical intervention. ${ }^{32}$

\section{Paradoxical response of tuberculomas to the treatment}

Paradoxical enlargement of pre-existing tuberculoma or appearance of new intracranial and spinal tuberculoma in patients receiving effective antituberculous therapy has been noted in the past. This paradoxical phenomenon is thought to be due to result of an immunological reaction. These lesions are usually discovered accidently when follow-up scan is performed routinely or when new neurological signs develop during the course of antitubercular therapy. Concomitant steroid therapy probably has a preventive role against these focal lesions. However, with continuation of antituberculous therapy, eventual resolution of these tuberculoma usually occurs. In case of unresponsiveness to medical therapy, surgery is recommended. 77,78

\section{Prognosis}

The single most important factor determining the prognosis in cases of CNS tuberculosis is the stage of tuberculous meningitis at which the treatment has been started. If treatment is started at stage I (prodromal phase with no definite neurological symptoms) the mortality and morbidity is very low, whereas in stage III (loss of sensorium, convulsions, focal neurological deficit, and involuntary movements) almost $50 \%$ patient die, and those who recover may have some form of neurological deficit. Stage II patients (signs of meningeal irritation, slight or no clouding of sensorium, minor cranial nerve palsies, and no neurological deficit) have intermediate prognosis. ${ }^{74,79}$

\section{Summary}

CNS tuberculosis is rare but serious complication and its early recognition and treatment is imperative. Early diagnosis can prevent further deterioration and result in better prognosis. Imaging plays a very important role in establishing the diagnosis of CNS tuberculosis. A radiologist should maintain a high degree of suspicion when patients with tuberculosis risk factors present with neurologic complains. Various imaging modalities, CSF studies, and brain biopsy if necessary, can aid in establishing the diagnosis of CNS tuberculosis. Pharmacological regimen is the mainstay of treatment, although various other options such as addition of corticosteroid and surgical intervention are also recommended as per requirement.

\section{References}

[1] Rich AR, Mccordock HA. Pathogenesis of tubercular meningitis. Bull John Hopkins Hosp 1933; 52:5-13.

[2] Leonard MK. Tuberculosis: forms of tuberculosis. 2002 Oct 1. Available at: www.medscape.com/viewarticle/534783?rssm Accessed May 25, 2006. 
[3] Dastur DK. Neurotuberculosis. In: Minckler J, ed. Pathology of the nervous system, Vol. 3. New York: McGraw-Hill 1972;2412-2422.

[4] Nicolls DJ, King M, Holland D, Bala J, del Rio C. Intracranial tuberculomas developing while on therapy for pulmonary tuberculosis. Lancet Infect Dis. 2005; 5(12):795-801.

[5] Bayindir C, Mete O, Bilgic B. Retrospective study of 23 pathologically proven cases of central nervous system tuberculomas. Clin Neurol Neurosurg. 2006;108 (4):353-357.

[6] Wallace RC, Brutons EM, Beret FF, et al. Intracranial tuberculosis in children. CT appearance and clinical outcome. Pediatric Radiol. 1991;21:241-246.

[7] Barkovich AJ. Infections of the nervous system. In: Barkovich AJ (Ed). Pediatric Neuroimaging (4th edn). Lippincott Williams and Wilkins 2005;801-805.

[8] Synder RD, Bacterial infections of the nervous system. In: Berg BO, ed. Neurologic aspects of pediatrics. Boston: Butterworth-Heinemann, 1992;195-226.

[9] Shah, GV. Central nervous system tuberculosis. Neuroimaging Clin North Am 2000;10(2),355-374.

[10] Klingensmith WC, Datu J, Tuberculous meningitis of the sylvian fissure. Clin Nucl Med. 1978; 3:315-317.

[11] Jamieson DH. Imaging intracranial tuberculosis in childhood. Paediatr Radiol.1995;25:165-170.

[12] Kioumehr F, Dadsetan MR, Rooholamini SA, et al. Central nervos system tuberculosis: MRI. Neuroradiology. 1994;36:93-96.

[13] Rovira M, Romero F, Torrent $\mathrm{O}$, et al. Intracranial tuberculoma. MR Imaging. Neuroradiology. 1989;31:299-302.

[14] Sheller JR, DesPrez RM. CNS tuberculosis. Neurol Clin 1986;4:143-158.

[15] Fischbein N, Dillon W, Barkovich A (Eds). Tuberculosis. In: Teaching atlas of brain imaging. Thieme 2000;165-168.

[16] Hsuh EY, Chi a LG, Shen We. Location of cerebral infarctions in tuberculous meningitis. Neuroradiol 1992;34:197.

[17] Reid H, Fallon RJ. Bacterial infections. In Adams JH Duchen L (Eds). Greenfields Neuropathology (5th edn). New York: Oxford University Press 1992;317-342.

[18] Gupta RK, Gupta S, Singh D, Sharma B, Kohli A, Gujral RB. MR imaging and angiography in tuberculous meningitis. Neuroradiol 1994;36:87-92.

[19] Garg RK, Tuberculosis of central nervous system. Postgrad Med J. 1999;75:133-140.

[20] Silverman IE, Liu GT, Bilaniuk LT, Volpe NJ, Galetta SL. Tuberculous meningitis with blindness and perichiasmal involvement on MRI. Pediatr Neurol. 1995;12(1):65-67.

[21] S. Prabhakar, R. Bhatia, V. Lal, Paramjeet Singh. Hypertrophic Pachymeningitis : Varied Manifestations of a Single Disease Entity. Neurol India. 2002;50: 45-52.

[22] Beşkonakli E, Çayli S, Turgut M, Yalçinlar Y. Primary giant granulomatous basal meningitis: An unusual presentation of tuberculosis. Child Nerv Syst 1998;14:79-81.

[23] Welchman JM. CT of intracranial tuberculomata. Clin Radiol 1979;30:567-579.

[24] Bhargava, Tandon PN. Intracranial tuberculomas: A CT study. Br J Radiol 1980;53:935945.

[25] Altenbesak S, Baytok V, Alhan E, et al. Suprasellar tuberculoma causing endocrinological disorders and initiating craniopharyngioma. Paeditr Neurosurg 1995;23:328-331.

[26] Esposito V, Fraioli B, Ferrante L, et al. Intrasellar tuberculoma: Case report. Neurosurgery 1987;21:721-723. 
[27] Sze G. Infections and inflammatory diseases. In:Stark DD, Bradley WG Jr. Magnetic resonance imaging. St. Louis, MO: CV Mosby, 1988:316-343.

[28] Desai K, Nadkarni T, Bhatjiwale M, Goel A. Intraventricular tuberculoma. Neurol Med Chir (Tokyo) 2002; 42:501-3.

[29] Van Dyk A. CT of intracranial tuberculosis with specific reference to the 'target sign.' Neuroradiology. 1988;30:329-336.

[30] Jinkins JR. Computed tomography of intracranial tuberculosis. Neuroradiology. 1991;33:126-135.

[31] Rajshekhar V, Haran RPO, Prakash GS, et al. Differentiating solitary small cysticercus granulomas and tuberculomas in patients with epilepsy. J Neurosurg 1993;78:402407.

[32] Jinkins JR. Gupta R, Chang KH, Rodriguez-Carbajal J. MR imaging of central nervous system tuberculosis. Radiol clin North Am 1995;33(4):771-789.

[33] Gupta RK, Jena A, Sharma DK, et al. MR imaging of intracranial tuberculomas. J Comput Assist Tomogr. 1988;12:280-285.

[34] Gupta RK, Prakash M, Mishra AM, et al. Role of diffusion weighted imaging in differentiation of intracranial tuberculoma and tuberculous abscess from cysticercus granulomas - a report of more than 100 lesions. Eur J Radiol. 2005;55(3):384-392.

[35] Gupta RK, Poptani M, Kohli A, et al. In vivo localized proton magnetic resonance spectroscopy of intracranial tubercolomas. Ind J Med Res. 1995;101:19-24.

[36] Gupta RK, Vatsal DK, Husain N, Chawla S, Prasad KN, Roy R, Kumar R, Jha D, Husain M. Differentiation of tuberculous from pyogenic brain abscesses with in vivo proton MR spectroscopy and magnetization transfer MR imaging. Am J Neuroradiol 2001;22:1503-1509.

[37] Gupta RK, Kathuria MK, Pradhan S. Magnetization transfer MR imaging in central nervous system tuberculosis. Am J Neuroradiol 1990;20:867-875.

[38] Whitener DR. Tuberculous brain abscess. Report of a case and review of the literature. Arch Neurol 1978;35:148-155.

[39] Bulakbasi N, Kocaoglu M, Ors F, Ucoz T. Combination of single-voxel proton MR spectroscopy and apparent diffusion coefficient calculation in the evaluation of common brain tumors. AJNR Am J Neuroradiol 2003;24:225-233.

[40] Kaminogo M, Ishimaru H, Morikawa M, Suzuki Y, Shibata S. Proton MR spectroscopy and diffusion weighted MR imagingfor the diagnosis of intracranial tuberculomas. Report of two cases. Neurol Res 2002;24:537-543.

[41] Withman RR, Johnson RH, Roberts DL. Diagnosis of military tuberculosis by cerebral computed tomography. Arch Intern Med 1979;139:479-480.

[42] Gee GT, Bazan C III, Jinkins JR. Miliary tuberculosis involving the brain: MR findings. AJR 1992;159:1075-1076.

[43] Dastur DK, Manghani DK, Udani PM. Pathology and pathogenetic mechanisms in neurotuberculosis. Radiol Clin North Am 1995;33:733-52.

[44] Udani PM, Dastur DK. Tuberculous encephalopathy with and without meningitis: clinical features and pathological correlations. J Neurol Sci 1970;10:541-61.

[45] Ng SH, Tang LM, Lui TN, et al. Tuberculoma en plaque: CT. Neuroradiology 1996; 38:453-5. 
[46] Dubey S, Devi BI, Jawalkar VK, Bhat DI. Tuberculoma en plaque: a case report. Neurol India 2002; 50:497-9.

[47] Villoria MF, Fortea F, Moreno S, Munoz L, Manero M, Benito C. MR imaging and CT of central nervous system tuberculosis in the patient with AIDS. Radiol Clin North Am. 1995 Jul:33(4):805-820.

[48] Bhaya A. Granulomatous hypophysitis - A rare entity mimicking pituitary adenoma. Indian J Radiol Imaging 1999;9:203-4.

[49] Diyora B, Kumar R, Modgi R, Sharma A. Calvarial tuberculosis: A report of eleven patients. Neurology India. 2009;57(5):607-612.

[50] Abhijit AR, Arpit MN, Datta M, Ashish JC, Ranjeet SN, Sudhir F and Veena LB. Imaging Features of Calvarial Tuberculosis: A Study of 42 Cases. American Journal of Neuroradiology 25:409-414, March 2004.

[51] Shenoy SN, Raja A. Tuberculous granuloma of the spheno-clival region. Neurology India. 2004; 52(1):129-130.

[52] Indira DB, Tyagi AK, Bhat DI, Santosh V. Tuberculous osteitis of clivus. Neurol India 2003;51:69-70.

[53] Narula MK, Chaudhary V, Baruah D, Kathuria M, Anand R. Pictorial essay: Orbital tuberculosis. Indian J Radiol Imaging. 2010;20:6-10.

[54] M.H. Rho, D.W. Kim, S.S. Kim, Y.S. Sung, J.S. Kwon, S.W. Lee. Tuberculous Otomastoiditis on High-Resolution Temporal Bone CT: Comparison with Nontuberculous Otomastoiditis with and without Cholesteatoma. AJNR Am J Neuroradiol.2007;28:493-496.

[55] McGuinness F. Tuberculous spondylitis. In McGuinness F (ed). Clinical imaging of nonpulmonary tuberculosis. Springer, Berline Heidelberg New York, pp 43-80.

[56] Sharif HS. Role of MR imaging in the management of spinal infections. AJR Am J Roentgenol.1992;158:1333-1345.

[57] Sharif HS, Morgan JL, Al-Shahed MS, et al: Role of CT and MR imaging in the management of tuberculous spondylitis. Radiol Clin North Am. 1995;33:787-804.

[58] Smith AS, Weinstein MA, Mizushima A et al: MR imaging of characteristics of tuberculous spondylitis vs vertebral osteomyelitis. AJNR. 1989;10:619-625.

[59] Akhaddar A, Gourinda H, Gazzaz M, Elmadhi T, Elalami Z, Miri A. Craniocervical junction tuberculosis in children. Rev Rhum Engl Ed. 1999;66(12):739-742.

[60] Allali F, Benomar A, EL Yahyaoui M, Chkili T, Hajjaj-Hassouni N . Atlantoaxial tuberculosis: three cases. Joint bone spine.2000;67(5):481-484.

[61] Zamiati W, Jiddane M, El Hassani MR, Chakir N, Boukkrissi N. Contribution of spiral CT scan and MRI in spinal tuberculosis (Spanish). J of Neuroradiology. J de Neuroradiologe. 1999;26:27-34.

[62] Resnick D. Tuberculous infection. In: Resnick D, ed. Diagnosis of bone and joint disorders. 3rd ed. London, United Kingdom: Saunders, 2002; 2524-2545.

[63] Dastur HM. Diagnosis and neurosusgical treatment of tuberculosis disease of the CNS. Neurosurg Rev 1983; 6: 111-17.

[64] Roca B. Intradural extramedullary tuberculoma of the spinal cord: a review of reported cases. J Infect. 2005;50(5):425-31.

[65] Ming Lu. Imaging Diagnosis of Spinal Intramedullary Tuberculoma:Case Reports and Literature Review. J Spinal Cord Med. 2010;33(2):159-162. 
[66] Shim DM, Kyum S, Kim TK, Chae SU. Intradural Extramedullary Tuberculoma Mimicking En Plaque Meningioma Clinics in Orthopedic Surgery 2010; 2:260-263.

[67] Sanser G, Guven C, Murat K, Bektas A. Syringomyelia and Intradural Extramedullary Tuberculoma of the Spinal Cord as a Late Complication of Tuberculous Meningitis. Turkish Neurosurgery 2010; 20: 561-565.

[68] SharmaA, Goyal M, Mishra NK, Gupta V, Gaikwad SB. MR imaging of tubercular spinal arachnoiditis. AJR Am J Roentgenol1997;168(3):807-812.

[69] Mohammad W, Hiba A, Bhojo K, Humera A. Neuroimaging of Tuberculous Myelitis: Analysis of Ten Cases and Review of Literature. Journal of Neuroimaging. 2006;16(3):197-205.

[70] Trivedi R, Saksena S, Gupta RK. Magnetic resonance imaging in central nervous system tuberculosis. Indian J Radiol Imaging. 2009 November; 19(4): 256-265.

[71] Harries A, Maher D. TB: a clinical manual for South East Asia. Geneva:World Health Organisation, 1997.

[72] Berger JR. Tuberculous meningitis. Curr Opin Neurol 1994;7:191-200.

[73] Small PM. Schecter GF, Goodman PC, Sande MA, Chaisson RE, Hopewell PC. Treatment of tuberculosis in patients with advanced human immunodeficiency virus infection. N Engl J Med 1991;324:289-94.

[74] Holdiness MR. Management of tuberculous meninglitis. Drugs 1990;39:224-33.

[75] Schoeman JF, Vanzyl LF, Laubscher JA, Donald PR. Effect of cortico- steroids on intracranial pressure, computed tomographic findings, and clinical outcome in young children with tuberculous meningitis. Pediatrics 1997;99:226-31.

[76] Leonard JM, Des Prez RM. Tuberculous meningitis. Infect Dis Clin North Am 1990;4:769-87.

[77] Afghani B, Lieberman JM: Paradoxical enlargement or development of intracranial tuberculomas during therapy : case report and review. Clin Infect Dis 1994;19:1092-1099.

[78] Nomura S, Akimura T, Kitahara T, Nagomi K, Suzuki M: Surgery for expansion of spinal tuberculoma during antituberculous chemotherapy: a case report. Pediatr Neurosurg 2001;35:153-157.

[79] Medical Research Council. Streptomycin in tuberculosis trials committee. Streptomycin treatment of tuberculous meningitis. Lancet 1948;i:582-96. 


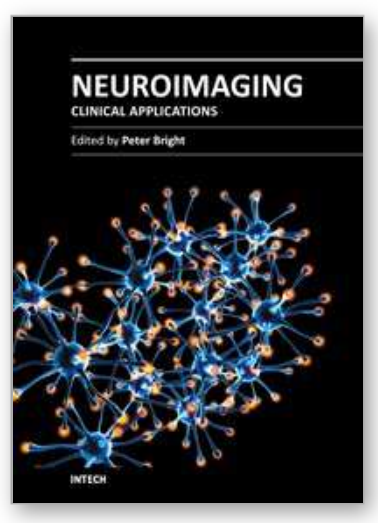

\author{
Neuroimaging - Clinical Applications \\ Edited by Prof. Peter Bright
}

ISBN 978-953-51-0200-7

Hard cover, 576 pages

Publisher InTech

Published online 09, March, 2012

Published in print edition March, 2012

Modern neuroimaging tools allow unprecedented opportunities for understanding brain neuroanatomy and function in health and disease. Each available technique carries with it a particular balance of strengths and limitations, such that converging evidence based on multiple methods provides the most powerful approach for advancing our knowledge in the fields of clinical and cognitive neuroscience. The scope of this book is not to provide a comprehensive overview of methods and their clinical applications but to provide a "snapshot" of current approaches using well established and newly emerging techniques.

\title{
How to reference
}

In order to correctly reference this scholarly work, feel free to copy and paste the following:

Shahina Bano, Vikas Chaudhary and Sachchidanand Yadav (2012). Central Nervous System Tuberculosis, Neuroimaging - Clinical Applications, Prof. Peter Bright (Ed.), ISBN: 978-953-51-0200-7, InTech, Available from: http://www.intechopen.com/books/neuroimaging-clinical-applications/central-nervous-systemtuberculosis

\section{INTECH}

open science | open minds

\section{InTech Europe}

University Campus STeP Ri

Slavka Krautzeka 83/A

51000 Rijeka, Croatia

Phone: +385 (51) 770447

Fax: +385 (51) 686166

www.intechopen.com

\section{InTech China}

Unit 405, Office Block, Hotel Equatorial Shanghai

No.65, Yan An Road (West), Shanghai, 200040, China

中国上海市延安西路65号上海国际贵都大饭店办公楼 405 单元

Phone: +86-21-62489820

Fax: +86-21-62489821 
(C) 2012 The Author(s). Licensee IntechOpen. This is an open access article distributed under the terms of the Creative Commons Attribution 3.0 License, which permits unrestricted use, distribution, and reproduction in any medium, provided the original work is properly cited. 